\title{
Computational Screening of Isolated Compounds From Goniothalamus Species to Identify Potential Inhibitors for Dengue Virus
}

Nor Nadirah Abdullah

Universiti Teknologi MARA

Syahrul Imran (D syahrulimran@uitm.edu.my )

Universiti Teknologi MARA https://orcid.org/0000-0001-7802-7359

Lam Kok Wai

Universiti Kebangsaan Malaysia

Nor Hadiani Ismail

Universiti Teknologi MARA

Research Article

Keywords: Goniothalamus species, DENV, Molecular docking, ADMET, Molecular Dynamics

Posted Date: December 8th, 2021

DOI: https://doi.org/10.21203/rs.3.rs-1115551/v1

License: () (1) This work is licensed under a Creative Commons Attribution 4.0 International License. Read Full License 


\section{Abstract}

In this study, a set of 234 chemical constituents reported from Goniothalamus species were docked against envelope (E), NS2B/NS3, NS5 methyltransferase, and NS5 RdRp dengue virus (DENV) protein. As the result, compounds 95, 96, 97, 100, 149, 155 , and 187 were identified as potential dengue protease inhibitors based on minimal docking energy values and multiple interactions with binding sites. The results from in-silico Lipinski' rule and ADMET analysis showed that compound 149 was predicted as the most potential compound that fulfills the drug-likeness properties. Ligand $\mathbf{1 4 9}$ was found to be able to fit in well and remain stable in the binding site of proteins envelope, NS2B/NS3, NS5 methyltransferase and NS5 RdRp. The results from molecular dynamic simulations indicate that the ligand-protein complex of 149 in NS5 methyltransferase showed the most preferable, successfully interacted within the active sites and were able to reach convergence within $100 \mathrm{~ns}$.

\section{Introduction}

Dengue fever has been a major concern around the world. The World Health Organization (WHO) estimated about 100-400 million dengue infections each year and about half of the world's population is now at risk. It is caused by the dengue virus (DENV), a member of the Flavivirus genus [1]. DENV consists of four serotypes named DENV-1, DENV-2, DENV-3, and DENV-4. DENV of serotype-2 has traditionally been studied in more detail than other serotypes because it is a more virulent strain [2-4]. The mature proteins for the dengue virus include three structural proteins (capsid (c), pre-membrane (prM), envelope (E)), and seven nonstructural proteins (NS1, NS2A, NS2B, NS3, NS4A, NS4B, and NS5). The E protein is essential for initial attachment of viral particles to host cell receptors. Thus, any disturbance in the function of E protein will prevent the dengue virus from attaching to the host cell receptors [5]. Inhibition of viral replication and infectivity will take place when there is any disruption in the NS3/NS2B complex region. Hence, NS3/NS2B complex is considered a promising target protein [6]. Besides, non-structural DENV protein NS5 also plays an important role in the inhibition of viral replication because of its dual enzymatic activity. The methyltransferase (MTase) domain protects viral mRNA from degradation through RNA capping (post-transcriptional modification), while RNA-dependent RNA-polymerase (RdRp) domain is responsible for the replication of positive-strand RNA within the host cell $[7,8]$.

Nowadays, there are a lot of treatments that use medicinal plants to inhibit virus replication [9]. Unfortunately, only a handful of research had been done on potential plants against the dengue virus. Goniothalamus species was reported to have secondary metabolites that are beneficial for activities like anti-tumor, anti-aging, anti-stress, and anti-malaria [10, 11]. The genus Goniothalamus (Family Annonaceae) were found to grow in the rainforest of tropical southeast Asia [12]. The most dominant classes of compounds present in this species are alkaloids, styryl-lactones, acetogenins, flavonoids, and fatty acids. Based on previous pharmacological studies, styryl lactones and acetogenins from Goniothalamus species are potent against anti-cancer cells such as kidney cells, breast, colon, and pancreatic carcinoma [13-16]. Previous studies showed that bioflavonoid quercetin exhibited significant anti-DENV replication properties [17]. Quercetin and fisetin affect intracellular DENV replication and can be proposed as candidate for anti-DENV therapeutics [17], while acetogenins can potentially inhibit DENV replication [18]. Styrylpyrone derivatives (SPD) from G. umbrosus root were also reported to show potential activity against dengue virus type 2 [60].

In continuation of our studies on compounds isolated from the roots and stembarks of the G. lanceolatus [28, 62], we aim to predict the possible compounds reported from the same genus of the plant that can interact well with target proteins for DENV. This study focuses on targeting structural DENV proteins envelope protein (E), non-structural DENV protease (NS3/NS2B), NS5 methyltransferase (MTase), and NS5 RNA-dependent RNA-polymerase (RdRp) protein. A set of plant-derived secondary metabolites isolated from Goniothalamus species were virtually screened against targeted DENV proteins through molecular docking and molecular dynamics (MD) simulation approaches. The set of compounds comprises different classes of compounds which are styryl-lactones, alkaloids, acetogenins, and flavonoids.

\section{Experimental}

\section{Selection of target protein}

Page 2/31 
Selecting the potential drug target or receptor that is responsible for the dengue replication process is the most important step in the drug designing procedure. Several target proteins for dengue virus that had been selected for this study include dengue virus envelope protein (E), protease (NS2B-NS3), helicase (NS3 helicase), methyltransferase (MTase), and the dengue virus RNAdependent RNA-polymerase (RdRp). The crystal structure of DENV target proteins were retrieved from the Protein Data Bank. Molecular docking was conducted using the three-dimensional crystal structure of dengue virus envelope protein (PDB:10KE); NS2B-NS3 (PDB:2FOM); NS5 methyltransferase (PDB:1R6A) and NS5 RdRp (PDB:3VWS).

\section{Ligand Database Preparation}

The comprehensive literature search was done to compile a set of 234 compounds phytochemicals previously isolated from Goniothalamus species and 12 reported protein inhibitors. The chemical structure of phytochemicals was taken from the online database of Dictionary of Natural Product (DNP), Pubchem, and ChEMBL. The structure was stored in .mol format. The energy minimization for each ligand was performed by using the MMFF94X force field.

\section{Molecular Docking}

The structure of isolated compounds from Goniothalamus species and reported DENV protein inhibitors were drawn by using ChemBioDraw ${ }^{\circledR}$ Ultra 13.0. The protein-ligand docking studies of the inhibitors and proposed drugs with the receptors 1OKE, 2FOM, 1R6A, and 3VWS were performed using validated CDOCKER protocol in Discovery Studio® 3.1 (Accelrys, San Diego, USA). This CDOCKER program generally employs CHARMm force fields as a grid-based molecular docking method. Water molecules and unwanted molecules from the crystal structure of the receptor were removed before performing docking experiments. The ligands conformations were generated through high-temperature molecular dynamics followed by random rotations and refinement by grid-based (GRID I) simulated annealing, full force field minimization, or final grid-based [26]. In this study, the cooling steps were set in 5000 steps to $300 \mathrm{~K}$ while for the heated steps, the temperature of $700 \mathrm{~K}$ in 2000 steps was used with the grid extension set to $10 \AA$. The top ten binding poses for each ligand were ranked based on their CDOCKER energies value.

To predict the best binding interaction, the top ten ranked poses per ligand were then analyzed. All the compounds were ranked based on the 1) interaction with an active residue of dengue protein; 2) binding energy value; 3) the total number of interactions and 4) bond distance. The idea was to select only those compounds that bind to the crucial amino acid of dengue protein with favorable docking energy value. To validate the docking protocol, the co-crystallized inhibitors were docked as reference ligands with non-structural E, NS3/NS2B, NS5 methyltransferase, and NS5 RdRp protein using CDOCKER to reproduce the binding interactions of ligands within the catalytic pockets.

\section{Molecular descriptors calculation}

Molecular properties and practicality of the compounds as drug candidates were determined based on the threshold set by "Lipinski's Rule of Five" through the Molinspiration server (www.molinspiration.com). The thirteen descriptors that include log-P, polar surface area, molecular weight, number of atoms, number of $\mathrm{O}$ or $\mathrm{N}$, number of $\mathrm{OH}$ or $\mathrm{NH}$, number of rotatable bonds, volume, G protein-coupled receptors (GPCR) ligand, ion channel modulator, a kinase inhibitor, and nuclear receptor ligand, and the number of violations to Lipinski's rule.

\section{ADMET analysis}

Pharmacokinetic studies are conventional methods to evaluate the drugs as they are being administered. Poor toxicity and clinical safety contribute to failures in drug discovery. To predict the level of clinical safety and toxicity, in-silico ADMET (Absorption, Distribution, Metabolism, Excretion, and Toxicity) analysis was performed using SwissADME (http://www.swissadme.ch/index.php). In-silico ADMET analysis gave information about human intestinal absorption (HIA), aqueous solubility (AS), blood-brain barrier (BBB), cytochrome P450 2D6 (CYP2D6), plasma protein binding (PPB), hepatotoxicity (HT), atom-based logP (Alog P98), and polar surface area (PSA) descriptors.

\section{Molecular Dynamic Simulation}

Page 3/31 
Molecular Dynamic simulations analysis were performed using Desmond v.2018 suite. The systems were set up using "System Builder" in Maestro. Energy minimization of complex 149 with target protein was performed by applying an enhanced Optimized Potentials for Liquid Simulations (OPLS3e) molecular mechanics force field, which was then placed in the cubic box with a buffer distance of $10 \AA$ to create a hydration model. Water molecules were placed between the ligand-receptor complex using a simple point charge (SPC) water model. The system was set to $2.0 \mathrm{fs}, 9 \AA, 300 \mathrm{~K}$, and $1.01325 \mathrm{bar}$ for the cut-off radius for time step, van der Waals, initial temperature, and pressure, respectively. To evaluate the electrostatic force of the Desmond system, near term and far term was divided by a boundary at $9 \AA$. Finally, MD simulations were performed under the NPT ensemble for $100 \mathrm{~ns}$. The result was recorded for every $50 \mathrm{ps}$ with a total of 2000 frames.

\section{Results And Discussion}

\section{Molecular Docking}

In this work, docking results were ranked based on these factors, 1) maximum hydrogen bond interaction with active site residues; 2) minimum binding energy value; 3) the total number of interactions; 4) bond distance. A total of 234 compounds previously reported from Goniothalamus species were screened (Table S1) and the top three ranked compounds were selected. Firstly, the validation of the docking procedure was done before carrying out molecular docking for the selected ligands. A co-crystalline ligand extracted from a selected crystallographic protease structure was re-docked into the same binding pocket. Based on the validation of the docking protocol with co-crystalline ligand, the RMSD value for 10KE (1.16 ̊), 1R6A (0.72 $⿱$ ) , and 3VWS (1.73 $)$ were below the $2.0 \AA$ threshold. NS3/NS2B developed an interesting active site that has a highly conserved catalytic triad (His51, Asp75, and Ser135) that is of prime functional importance. Any interaction that takes place in this active site will result in the inhibition of viral replication [2].

The top-ranked compounds were ranked based on their minimum docking energy value and a maximum number of interactions with active site residues. The molecules that can disrupt virus-host binding and inhibiting the entry of virus particles into target cells can be considered as potential inhibitors. Envelope protein is a vital protease because it is crucial for the initial attachment of viral particles to host cell receptors. Thus, any compound that can disrupt E protein activity can already be considered as a lead compound towards anti-DENV drug discovery [19]. The chemical structure of top ranked compounds was drawn and listed in figure 1 . The results of docking studies showed that compounds $96, \mathbf{9 7}$, and 149 can bind well to the active site of DENV E protein. Among these three, xylomaticinone was selected for having a minimum number of docking energy values and a maximum number of interactions with the crucial amino acid residues. However, due to the large molecular weight (MW $\leq 500)$, acetogenin compounds like $\mathbf{9 6}$ and $\mathbf{9 7}$ have poor pharmacokinetic properties and therefore it was not further pursued as potential inhibitors for envelope protein.

Compound 149 passes all the Lipinski rule's criteria and has the docking energy value of $-45.9 \mathrm{kcal} / \mathrm{mol}$ (Table 1). This compound binds to the enzyme through hydrogen bonding with the active residue such as Lys128 and Thr48 while being stabilized by other residues through hydrophobic interactions. The ligand-enzyme complex was stabilized by a carbon-hydrogen bond interaction with Thr48 at $2.54 \AA$ and $2.83 \AA$ (Fig. 2). The compound is further stabilized through more contacts in the form of $\pi-\pi$ interactions with the binding site amino acids, Ala50, Pro53, and lle270. These $\pi-\pi$ interactions are necessary to obtain stronger and more selective binding interactions. This ligand-enzyme complex also displayed the presence of electrostatic attraction in the form of a salt bridge in protein (Lys128-1.69 A). The binding of compound 149 to envelope protein prevents protein-protein interaction between DENV-2 and host cells during infection. Hence, this compound has potential in preventing the attachment and entry process.

NS3/NS2B was considered to have a central role in enhancing viral replication in the host cells. Allosteric pockets of NS3/NS2B protease were located close to its catalytic triad (His51, Asp75, Ser135), so any close interaction with residues in an allosteric pocket will disrupt the activities of the protease [61]. Residues His51, Asp75, Gly133, Ser135, Gly151, Asn152, and Gly153 are located in the active site regions, and it is crucial for ligand interactions with NS3/NS2B protease inhibitors while residues Lys74, Leu76, Asn152, Trp83, Leu149, Gly148, and Glu88 are important residue near to allosteric pockets for NS3/NS2B [19,20]. Compounds 100 and 155 both have interactions with the catalytic triad (His51) and exhibited the minimum docking energy value, 
but these two compounds have several violations towards drug-likeness test due to the large molecular weight and large value of octanol-water partition coefficient so, these two acetogenins were not further investigated. The results showed that 149 produced a docking energy value of $-25.9 \mathrm{kcal} / \mathrm{mol}$. Even though 149 does not interact with the catalytic triad, this compound has several interactions with the active residues (Lys74, Leu76, and Asn152) in the allosteric pocket that is crucial for an inhibitor. The ligandenzyme complex was stabilized by a conventional hydrogen bond $(\mathrm{N}-\mathrm{-HO})$ of hydrogen from the hydroxyl group of a compound with the nitrogen of amine from residue Asn 152 and Lys74. Compound 149 also forms carbon-hydrogen bonding with other residues, Gly87 (2.50 A), Gly87 (2.56 Å), and Val147 (2.50 ̊̊).

This complex was further stabilized by $\pi-\pi$ interactions with the binding sites involving Ala166, and Leu76 (Fig. 3). Furthermore, salt bridge interaction between lysine (Lys74-1.69 $\AA$ ) residues and electrostatic charge at the oxygen of hydroxyl group from the ligand side chain also play an important role to stabilize the complex. Thus, any interaction with these residues in the allosteric pocket of the active site will enhance the inhibition activities in the processing of polyprotein during the replication of virus dengue.

Besides, both NS5 methyltransferase and NS5 RdRp are crucial for the inhibition of viral replication [7]. Compound 149 showed the best docking interaction for both proteases due to the maximum number of interactions with active residues and without having any violation for the drug-likeness test. Compound 149 showed the best docking interaction with IR6A with a docking energy value of $-53.6 \mathrm{kcal} / \mathrm{mol}$. The stability of the ligand-enzyme complex is based on the carbon-hydrogen bond with the following active residues (Ser150, Lys29, Pro152, and Lys22). The results displayed $\pi-\pi$ interactions with the binding sites involving Phe25 and Pro152 (Fig. 4). This complex was further stabilized by two electrostatic attractions between oppositely charged residues that are sufficiently close to each other (Lys22-1.63 $\AA$ and Lys29-1.69 $\AA$ ). Compound 149 also showed the best docking interaction with the 3VWS protease enzyme with a docking energy value of $-56.8 \mathrm{kcal} / \mathrm{mol}$. This compound binds to the enzyme through conventional hydrogen bonding with the active residue Thr413 and Asn 405 and is further stabilized by other residues through hydrophobic interactions. This compound is able to form $\pi-\pi$ interactions with Trp795 (5.00 $\AA$ ) and attractive charge interaction with $\operatorname{Arg} 792$ at $2.88 \AA$ (Fig. 5). As mentioned above, compound 149 is bound to a common active site residue that is structurally and functionally important for NS5 dengue proteases.

Eighteen flavones showed favorable binding energy of less than $-56.8 \mathrm{kcal} / \mathrm{mol}$. Overall, from the docking results, compound $\mathbf{1 4 9}$ was observed to have the highest affinity with E, NS3/NS2B, NS5 methyltransferase, and NS5 RdRp. This compound successfully fits in the binding site of the protein and forms the most number of interactions with the active site residues at the lowest docking energy value. Compound $\mathbf{1 4 9}$ is a quercetin derivative, which is known as 3-O-methylquercetin because of the presence of four hydroxy and one methoxy group. The presence of hydroxyl groups at C5, C7, C3' and C4' on the phenyl rings produces a resonance phenomenon. The electrons from the hydroxyl group are delocalized into the aromatic ring. Hence, this facilitates the formation of hydrogen bonding with the residues in the protein binding sites. In addition, the methoxy group at the C3 position could enhance the overall binding interactions (Fig. S1). This compound was reported to display antioxidant and free radical scavenging activities [21]. Besides, 3-O-methylquercetin also displayed several in vitro and in vivo biological activities such as anti-inflammatory, neuroprotective, bronchodilatory, vasodilatory, antinociceptive, immunomodulatory, antitumor, and antiviral [22].

The acetogenins were observed to have a minimal docking energy value lower than $-59.0 \mathrm{kcal} / \mathrm{mol}$. This is due to the long alkyl chain in the skeleton that could enhance the interactions with the protein target. However, acetogenins normally have molecular weights of more than 500, which causes difficulty in terms of fitting in the protein binding site and not being absorbed through the gastrointestinal tract. Styryl-lactones are the dominant class of compounds in this genus, but they were found to exhibit poor binding energy of less than $-33.1 \mathrm{kcal} / \mathrm{mol}$ while alkaloids were observed to have even lower binding energy than $-25.8 \mathrm{kcal} / \mathrm{mol}$.

Table 1 Result of top-three ranked phytochemicals screened against the targeted protein (HB-IR: Hydrogen bond Interaction; HDPIR: Hydrophobic Interaction; PI-IR: Pi-Interaction) 


\begin{tabular}{|c|c|c|c|c|c|c|c|c|}
\hline \multirow{2}{*}{$\begin{array}{l}\text { Protein } \\
\text { (PDB ID) }\end{array}$} & \multirow[t]{2}{*}{ Ligand } & \multirow{2}{*}{$\begin{array}{l}\text { Docking } \\
\text { energy } \\
(\mathrm{kcal} / \mathrm{mol})\end{array}$} & \multicolumn{2}{|l|}{ HB-IR-Å } & \multicolumn{2}{|l|}{ HDP-IR-Å } & \multicolumn{2}{|l|}{ PI-IR-Å } \\
\hline & & & $\begin{array}{l}\text { Residue/ } \\
\text { Distance } \\
(\AA)\end{array}$ & $\begin{array}{l}\text { Type of } \\
\text { interaction }\end{array}$ & $\begin{array}{l}\text { Residue/ } \\
\text { Distance } \\
(\AA)\end{array}$ & $\begin{array}{l}\text { Type of } \\
\text { interaction }\end{array}$ & $\begin{array}{l}\text { Residue/ } \\
\text { Distance } \\
(\AA)\end{array}$ & $\begin{array}{l}\text { Type of } \\
\text { interaction }\end{array}$ \\
\hline \multirow{16}{*}{$\begin{array}{l}\text { E } \\
(10 K E)\end{array}$} & \multirow[t]{5}{*}{96} & \multirow[t]{5}{*}{-46.1} & $\begin{array}{l}\text { Thr189 } \\
(2.29)\end{array}$ & $\begin{array}{l}\text { Conventional } \\
\text { H-bond }\end{array}$ & $\begin{array}{l}\text { Gln271 } \\
(2.31)\end{array}$ & $\begin{array}{l}\text { Unfavorable } \\
\text { donor-donor }\end{array}$ & \multirow[t]{5}{*}{$\begin{array}{l}\text { Phe193 } \\
(5.16)\end{array}$} & \multirow[t]{5}{*}{ Pi-alkyl } \\
\hline & & & $\begin{array}{l}\text { Leu191 } \\
(2.42)\end{array}$ & $\begin{array}{l}\text { Conventional } \\
\text { H-bond }\end{array}$ & $\begin{array}{l}\text { Ala50 } \\
(2.53)\end{array}$ & $\begin{array}{l}\text { Unfavorable } \\
\text { donor-donor }\end{array}$ & & \\
\hline & & & $\begin{array}{l}\text { Thr189 } \\
(2.97)\end{array}$ & $\begin{array}{l}\text { Carbon } \mathrm{H}- \\
\text { bond }\end{array}$ & $\begin{array}{l}\text { Ala205 } \\
(4.57)\end{array}$ & & & \\
\hline & & & & & $\begin{array}{l}\text { Leu198 } \\
(5.37)\end{array}$ & \multirow[t]{2}{*}{ Alkyl } & & \\
\hline & & & & & $\begin{array}{l}\text { Leu198 } \\
(5.37)\end{array}$ & & & \\
\hline & \multirow[t]{5}{*}{97} & \multirow[t]{5}{*}{-48.4} & $\begin{array}{l}\text { Ala50 } \\
(1.97)\end{array}$ & $\begin{array}{l}\text { Conventional } \\
\mathrm{H} \text {-bond }\end{array}$ & $\begin{array}{l}\text { Leu191 } \\
(4.11)\end{array}$ & \multirow{5}{*}{$\begin{array}{l}\text { Alkyl } \\
\text { Alkyl } \\
\text { Alkyl } \\
\text { Alkyl } \\
\text { Alkyl }\end{array}$} & \multirow[t]{5}{*}{$\begin{array}{l}\text { Phe279 } \\
(5.18)\end{array}$} & \multirow[t]{5}{*}{ Pi-alkyl } \\
\hline & & & \multirow[t]{4}{*}{$\begin{array}{l}\text { Gly190 } \\
(2.60)\end{array}$} & \multirow[t]{4}{*}{$\begin{array}{l}\text { Carbon } \mathrm{H}- \\
\text { bond }\end{array}$} & $\begin{array}{l}\text { Leu277 } \\
(4.38)\end{array}$ & & & \\
\hline & & & & & $\begin{array}{l}\text { Pro53 } \\
(4.62)\end{array}$ & & & \\
\hline & & & & & $\begin{array}{l}\text { Ala50 } \\
(5.16)\end{array}$ & & & \\
\hline & & & & & $\begin{array}{l}\text { Leu207 } \\
(5.25)\end{array}$ & & & \\
\hline & \multirow[t]{6}{*}{149} & \multirow[t]{6}{*}{-45.9} & \multirow{2}{*}{$\begin{array}{l}\text { Pro53 } \\
(2.44) \\
\text { Thr48 } \\
(2.54)\end{array}$} & $\begin{array}{l}\text { Carbon } \mathrm{H}- \\
\text { bond }\end{array}$ & \multirow[t]{6}{*}{$\begin{array}{l}\text { Lys128 } \\
(1.69)\end{array}$} & \multirow[t]{6}{*}{ Salt bridge } & $\begin{array}{l}\text { Ala50 } \\
(3.10)\end{array}$ & \multirow{2}{*}{$\begin{array}{l}\text { Pi-donor } \\
\text { Pi-alkyl } \\
\text { Pi-alkyl }\end{array}$} \\
\hline & & & & $\begin{array}{l}\text { Carbon } \mathrm{H}^{-} \\
\text {bond }\end{array}$ & & & $\begin{array}{l}\text { Ala50 } \\
(4.13)\end{array}$ & \\
\hline & & & \multirow[t]{4}{*}{$\begin{array}{l}\text { Thr48 } \\
(2.83)\end{array}$} & \multirow[t]{4}{*}{$\begin{array}{l}\text { Carbon } \mathrm{H}- \\
\text { bond }\end{array}$} & & & $\begin{array}{l}\text { Ala50 } \\
(4.33)\end{array}$ & \multirow{4}{*}{$\begin{array}{l}\text { Pi-alkyl } \\
\text { Pi-alkyl } \\
\text { Pi-alkyl }\end{array}$} \\
\hline & & & & & & & $\begin{array}{l}\text { Pro53 } \\
\text { (4.94) }\end{array}$ & \\
\hline & & & & & & & $\begin{array}{l}\text { Ala50 } \\
(5.01)\end{array}$ & \\
\hline & & & & & & & $\begin{array}{l}\text { lle270 } \\
(5.48)\end{array}$ & \\
\hline \multirow[t]{5}{*}{$\begin{array}{l}\text { NS3/NS2B } \\
\text { (2FOM) }\end{array}$} & \multirow[t]{3}{*}{100} & \multirow[t]{3}{*}{-36.7} & $\begin{array}{l}\text { Glu88 } \\
(1.98)\end{array}$ & $\begin{array}{l}\text { Conventional } \\
\mathrm{H} \text {-bond }\end{array}$ & $\begin{array}{l}\text { Ala164 } \\
(3.50)\end{array}$ & \multirow{3}{*}{$\begin{array}{l}\text { Alkyl } \\
\text { Alkyl } \\
\text { Alkyl }\end{array}$} & $\begin{array}{l}\text { His51 } \\
(4.19)\end{array}$ & Pi-alkyl \\
\hline & & & $\begin{array}{l}\text { Glu86 } \\
(2.74)\end{array}$ & $\begin{array}{l}\text { Carbon } \mathrm{H}- \\
\text { bond }\end{array}$ & $\begin{array}{l}\text { Val154 } \\
(4.93)\end{array}$ & & & \\
\hline & & & $\begin{array}{l}\text { Asn152 } \\
(2.77)\end{array}$ & $\begin{array}{l}\text { Carbon } \mathrm{H}- \\
\text { bond }\end{array}$ & $\begin{array}{l}\text { lle123 } \\
(4.94)\end{array}$ & & & \\
\hline & 149 & -25.9 & $\begin{array}{l}\text { Asn152 } \\
(2.32)\end{array}$ & $\begin{array}{l}\text { Conventional } \\
\text { H-bond }\end{array}$ & $\begin{array}{l}\text { Lys74 } \\
(1.69)\end{array}$ & Salt bridge & $\begin{array}{l}\text { Ala166 } \\
(2.78)\end{array}$ & Pi-sigma \\
\hline & & & $\begin{array}{l}\text { Lys74 } \\
(2.56)\end{array}$ & $\begin{array}{l}\text { Conventional } \\
\mathrm{H} \text {-bond }\end{array}$ & & & $\begin{array}{l}\text { Gol202 } \\
(2.99)\end{array}$ & pair \\
\hline
\end{tabular}

Page 6/31 


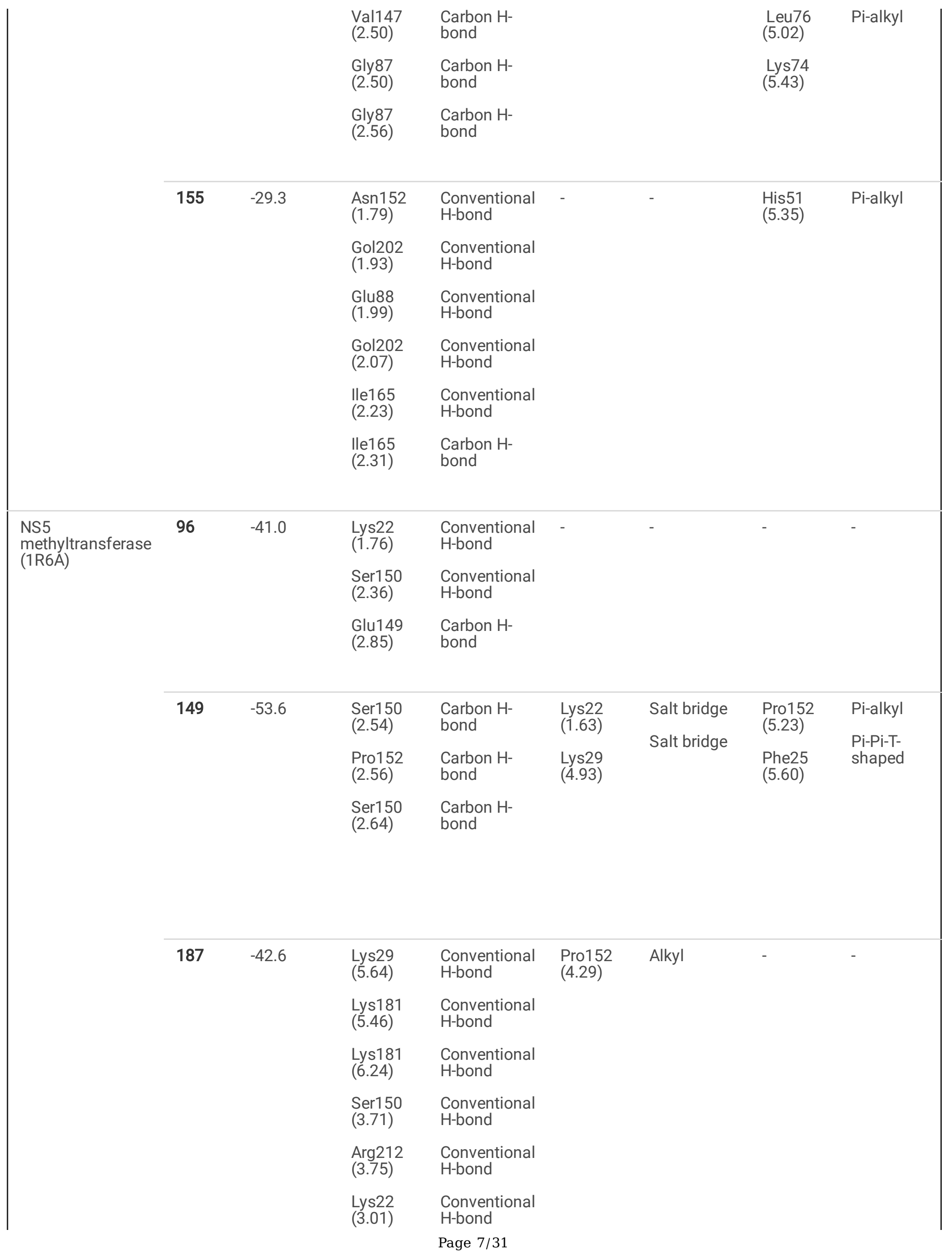




\begin{tabular}{|c|c|c|c|c|c|c|c|c|}
\hline & & & $\begin{array}{l}\text { Lys22 } \\
(3.76)\end{array}$ & $\begin{array}{l}\text { Conventional } \\
\mathrm{H} \text {-bond }\end{array}$ & & & & \\
\hline & & & $\begin{array}{l}\text { SO4904 } \\
(3.37)\end{array}$ & $\begin{array}{l}\text { Conventional } \\
\mathrm{H} \text {-bond }\end{array}$ & & & & \\
\hline & & & $\begin{array}{l}\text { Thr213 } \\
(5.18)\end{array}$ & $\begin{array}{l}\text { Carbon H- } \\
\text { bond }\end{array}$ & & & & \\
\hline $\begin{array}{l}\text { NS5 RdRp } \\
\text { (3VWS) }\end{array}$ & 95 & -54.8 & $\begin{array}{l}\text { Ser796 } \\
(2.80)\end{array}$ & $\begin{array}{l}\text { Conventional } \\
\mathrm{H} \text {-bond }\end{array}$ & $\begin{array}{l}\text { Lys401 } \\
(4.77)\end{array}$ & Alkyl & - & - \\
\hline & & & $\begin{array}{l}\text { His798 } \\
(3.27)\end{array}$ & $\begin{array}{l}\text { Carbon H- } \\
\text { bond }\end{array}$ & $\begin{array}{l}\text { Ile797 } \\
(5.19)\end{array}$ & & & \\
\hline & 96 & -59.0 & $\begin{array}{l}\text { Arg792 } \\
(2.88)\end{array}$ & $\begin{array}{l}\text { Conventional } \\
\text { H-bond }\end{array}$ & $\begin{array}{l}\text { Arg352 } \\
(4.92)\end{array}$ & Alkyl & $\begin{array}{l}\text { His800 } \\
(5.08)\end{array}$ & Pi-alkyl \\
\hline & 149 & -56.8 & $\begin{array}{l}\text { Thr413 } \\
(3.08)\end{array}$ & $\begin{array}{l}\text { Conventional } \\
\text { H-bond }\end{array}$ & $\begin{array}{l}\text { Arg792 } \\
(2.88)\end{array}$ & $\begin{array}{l}\text { Attractive } \\
\text { charge }\end{array}$ & $\begin{array}{l}\text { Trp795 } \\
(5.00)\end{array}$ & $\begin{array}{l}\text { Pi-Pi-T- } \\
\text { shaped }\end{array}$ \\
\hline & & & $\begin{array}{l}\text { Asn405 } \\
(3.32)\end{array}$ & $\begin{array}{l}\text { Conventional } \\
\mathrm{H} \text {-bond }\end{array}$ & & & & \\
\hline
\end{tabular}

Table 2 Result of top-ranked reported protein inhibitor screened against E, NS3/NS2B, NS5 methyltransferase, NS5 RdRp DENV proteins with their respective docking energy value and interacting residue in the binding site. 


\begin{tabular}{|c|c|c|c|c|c|c|}
\hline Protein & $\begin{array}{l}\text { PDB } \\
\text { ID }\end{array}$ & Inhibitor & State & $\begin{array}{l}\text { Mode of } \\
\text { action }\end{array}$ & $\begin{array}{l}\text { Docking } \\
\text { energy } \\
\text { (kcal/mol) }\end{array}$ & Reference \\
\hline \multirow[t]{3}{*}{ Envelope (E) } & \multirow[t]{3}{*}{ 10KE } & D02 & $\begin{array}{l}\text { D02 inhibits the virus life cycle. } \\
\text { It is also reduced viral } \\
\text { replication activity }\end{array}$ & $\begin{array}{l}\text { E protein } \\
\text { BOG pocket }\end{array}$ & -37.3 & 51 \\
\hline & & PO2 & $\begin{array}{l}\text { P02 inhibits viral replication at } \\
\text { micromolar concentrations. }\end{array}$ & $\begin{array}{l}\text { E protein } \\
\text { BOG pocket }\end{array}$ & -26.3 & 51 \\
\hline & & A5 & $\begin{array}{l}\text { A5 has low micromolar activity } \\
\text { against DENV }\end{array}$ & $\begin{array}{l}\text { E protein } \\
\text { BOG pocket }\end{array}$ & -25.9 & 52 \\
\hline \multirow[t]{3}{*}{ NS3/NS2B } & \multirow[t]{3}{*}{$2 \mathrm{FOM}$} & Compound 23i & $\begin{array}{l}\text { Compound 23i showed DENV } \\
\text { NS2B-NS3 protease inhibition } \\
\text { activity. This compound } \\
\text { showed antiviral activity } \\
\text { against DENV in vitro and } \\
\text { maybe a good lead for } \\
\text { discovering new therapeutic } \\
\text { agents for DENV. }\end{array}$ & $\begin{array}{l}\text { Competitive } \\
\text { inhibition } \\
\text { protease }\end{array}$ & -32.6 & 53 \\
\hline & & BP13944 & $\begin{array}{l}\text { BP13944 inhibited viral } \\
\text { replication and RNA synthesis } \\
\text { in all four DENV serotypes. }\end{array}$ & $\begin{array}{l}\text { Competitive } \\
\text { inhibition } \\
\text { protease }\end{array}$ & -28.4 & 54 \\
\hline & & Compound 32 & $\begin{array}{l}\text { This compound has an } \\
\text { inhibitory effect on DENV } \\
\text { replication and is determined in } \\
\text { a dose-dependent manner. } \\
\text { Cytotoxicity is cell culture is } \\
\text { unknown. }\end{array}$ & $\begin{array}{l}\text { Competitive } \\
\text { inhibition } \\
\text { protease }\end{array}$ & -27.5 & 55 \\
\hline \multirow{4}{*}{$\begin{array}{l}\text { NS5 } \\
\text { methyltransferase }\end{array}$} & \multirow{4}{*}{$1 \mathrm{R} 6 \mathrm{~A}$} & NSC14778 & $\begin{array}{l}\text { NSC14778 is a low-micromolar } \\
\text { inhibitor }\end{array}$ & $\begin{array}{l}\text { MTase } \\
\text { active site. }\end{array}$ & -35.2 & 56 \\
\hline & & & of DENV-2 MTase. & $\begin{array}{l}\text { The llgand } \\
\text { binds to the } \\
\text { SAM site }\end{array}$ & & \\
\hline & & Sinefungin & $\begin{array}{l}\text { The affinity for Sinefungin is } \\
\text { approximately six times higher } \\
\text { than for SAM. Sinefungin is } \\
\text { non-cell permeable. }\end{array}$ & $\begin{array}{l}\text { MTase } \\
\text { active site. } \\
\text { The ligand } \\
\text { binds to the } \\
\text { SAM site }\end{array}$ & -25.5 & 57 \\
\hline & & $\begin{array}{l}\text { Guanosine } \\
\text { monophosphate } \\
\text { (GMP) }\end{array}$ & GMP is non-cell permeable. & $\begin{array}{l}\text { MTase GTP } \\
\text { pocket }\end{array}$ & -24.1 & 57 \\
\hline \multirow[t]{3}{*}{ NS5 RdRp } & \multirow[t]{3}{*}{ 3VWS } & ddGTP & $\begin{array}{l}\text { ddGTP showed low micromolar } \\
\text { IC50 values in in vitro DENV-2 } \\
\text { RdRp activity tests using a } \\
\text { poly(rC) template }\end{array}$ & $\begin{array}{l}\text { RdRp non- } \\
\text { nucleoside }\end{array}$ & -53.5 & 58 \\
\hline & & Balapiravir & $\begin{array}{l}\text { Balapiravir failed to be effective } \\
\text { for patients with DENV. No } \\
\text { efficacy was found in the phase } \\
\text { II Clinical trial }\end{array}$ & $\begin{array}{l}\text { Cytidine } \\
\text { nucleoside }\end{array}$ & -48.5 & 57 \\
\hline & & NITD 203 & $\begin{array}{l}\text { NITD } 203 \text { showed in vivo } \\
\text { toxicity after } 2 \text { weeks of } \\
\text { administration in rats and dogs. }\end{array}$ & $\begin{array}{l}\text { RdRp non- } \\
\text { nucleoside }\end{array}$ & -42.4 & 59 \\
\hline
\end{tabular}

For comparison purposes, twelve reported protease inhibitors obtained from previous studies (Table 2) were docked into the specific target protein. Their result showed that the docking energy value ranged from -24.0 to $-53.0 \mathrm{kcal} / \mathrm{mol}$. Most of the reported inhibitors showed different interactions with the target protein of the binding pockets. Among these reported inhibitors, compound 23i was observed to have no interaction at all with the catalytic triad but produces hydrogen bond interactions with amino acid residues Asn152, Asn167, and Ala166. Other than that, for envelope DENV protein, D02 was found to interact with 
crucial amino acid residues (Lys128 and Ala50) and another active amino acid (Pro53 and lle270). For NS5 methyltransferase DENV protein, NSC14778 exhibited interaction with three crucial amino acid residues and several interactions with other active amino acids. These inhibitors can form hydrogen bonds with Lys14, Ser214, and Lys22, $\pi$-interaction with Phe25, and salt-bridge interactions with Lys14 and Lys22.

In addition, ddGTP inhibits the NS5 RdRp DENV protein by forming a hydrogen bond interaction with crucial amino acid (Lys401) and several interactions with other active site residues (Arg792, Gly601, Trp795, Asn492, Asn405, Thr413, Val603, and Phe412). Moreover, it also has the ability to interact with Cys331 (Fig. 8). From the findings, most of the top-ranked phytochemicals from Goniothalamus sp. exhibited good binding interaction as compared to reported inhibitors based on the docking energy value and the maximum number with crucial amino acids. Several compounds showed a maximum interaction with crucial amino acid residues that makes them potential lead compounds for anti-dengue drug discovery.

\section{Drug-likeness and ADMET}

Drug scan tools at Molinspiration and SwissADME server predict the drug-likeness of the proposed DENV inhibitors. All ligands were checked for their physicochemical properties through the filter of Lipinski rule of 5 . The nine descriptors include octanolwater partition coefficient (Log-P), polar surface area (TPSA), number of non-hydrogen atoms, molecular weight (MW), number of hydrogen bond acceptors [ $\mathrm{O}$ and $\mathrm{N}$ atoms], number of hydrogen bond donors [OH and $\mathrm{NH}$ groups], number of rules of 5 violations, number of rotatable bonds and molecular volume are taken into consideration. Among these phytochemicals, only 149 passed all the drug-likeness tests without any violation (Table 3). The remaining acetogenins had some violations because of the molecular weight of more than 500, Log-P value bigger than 5 and exceeding the number of hydrogen bond donors ( $\leq 5)$. The phytochemical that successfully passed all these parameters is predicted and considered as potential lead compounds with the good pharmacokinetic property.

Based on the results, compound $149(\mathrm{C} 16 \mathrm{H} 12 \mathrm{O})$ is the only phytochemical that passed the drug-likeness analyses without any violations. ADMET analyses were further conducted to predict the inhibitor's capability of drug-likeness. This analysis was conducted based on several parameters, physicochemical property, absorption, distribution, metabolism, and toxicity. These parameters have then been evaluated based on the number of thresholds. The results showed that all the acetogenins compounds are not qualified for certain parameters. However, the ADME prediction result for compound 149 inhibitors were predicted to pass the ADMETsar threshold of drug ability (Table 4).

Table 3 Molecular physicochemical descriptors analysis of nine ligands using Molinspiration online software tools.

\begin{tabular}{|llllllllll|}
\hline Ligands & Log Pa $^{\mathrm{a}}$ & TPSA $^{\mathrm{b}}$ & ${\text { Nato } \mathrm{ms}^{\mathrm{c}}}^{\mathrm{N}}$ & $\mathrm{MW}^{\mathrm{d}}$ & $\mathrm{noN}^{\mathrm{e}}$ & $\mathrm{nOH} \mathrm{NH}^{\mathrm{f}}$ & Nviolations $^{\mathrm{g}}$ & Nrotb $^{\mathrm{h}}$ & Volume $^{\mathrm{i}}$ \\
\hline $\mathbf{9 5}$ & 9.48 & 72.84 & 43 & 606.97 & 5 & 1 & 2 & 28 & 659.42 \\
\hline $\mathbf{9 6}$ & 9.45 & 93.07 & 46 & 651.03 & 6 & 2 & 2 & 30 & 701.07 \\
\hline $\mathbf{9 7}$ & 9.32 & 93.07 & 45 & 637.00 & 6 & 2 & 2 & 29 & 684.26 \\
\hline 100 & 8.48 & 113.29 & 45 & 638.97 & 7 & 3 & 2 & 28 & 675.51 \\
\hline 149 & 1.96 & 120.36 & 23 & 316.26 & 7 & 4 & 0 & 2 & 257.61 \\
\hline 155 & 8.51 & 153.75 & 46 & 656.94 & 9 & 5 & 2 & 31 & 678.80 \\
\hline 187 & 7.52 & 173.98 & 47 & 672.94 & 10 & 6 & 3 & 31 & 686.85 \\
\hline
\end{tabular}

${ }^{a}$ Octanol-Water partition coefficient (expressed as LogP, acceptable range: $₫ 5$ ), ${ }^{b}$ Polar surface area, ${ }^{c}$ Number of non-hydrogen atoms, ${ }^{\mathrm{d}}$ Molecular weight (acceptable range: <500), eNumber of hydrogen bond acceptors [O and $\mathrm{N}$ atoms] (acceptable range: $\leq 10),{ }^{f}$ Number of hydrogen bond donors [OH and $\mathrm{NH}$ groups] (acceptable range: $\leq 5$ ), ${ }^{g}$ Number of Rule of 5 violations, ${ }^{\mathrm{h}}$ Number of rotatable bonds, 'Molecular volume.

The ADME prediction result for compound 149 showed some solubility (Log S) with value -3.88 . The distribution coefficient $P$ ( $\log P$ ) for this compound was 1.96 (should be between -0.7 and +5.0 ). The compounds were unable to permeate BBB and act 
as non-substrate of P-glycoprotein. However, this compound was considered as an inhibitor for enzyme CYP1A2, CYP23A4, CYP2C9 and CYP2D6 subtypes. From this in-silico ADME analysis, compound $\mathbf{1 4 9}$ also was predicted to have no hepatotoxicity and did not have the plasma protein binding (PPB) ability. The results of Lipinski's calculation and ADME analysis indicated that compound $\mathbf{1 4 9}$ is the most selected among others due to the zero violations in Lipinski's rule of five and it was also predicted as a potential inhibitor by ADME analysis.

Table 4 ADMET Profiling Enlisting Absorption, Distribution, Metabolism and Toxicity related drug-likeness parameters. 


\begin{tabular}{|c|c|c|c|c|c|c|c|}
\hline Models & 95 & 96 & 97 & 100 & 149 & 155 & 187 \\
\hline \multicolumn{8}{|l|}{$\begin{array}{l}\text { 1. Physicochemical } \\
\text { Property }\end{array}$} \\
\hline \multirow[t]{2}{*}{ Solubility (Log S) } & -9.68 & -9.77 & -9.41 & -7.95 & -3.88 & -7.04 & -6.52 \\
\hline & $\begin{array}{l}\text { (Poorly } \\
\text { soluble) }\end{array}$ & $\begin{array}{l}\text { (Poorly } \\
\text { soluble) }\end{array}$ & $\begin{array}{l}\text { (Poorly } \\
\text { soluble) }\end{array}$ & $\begin{array}{l}\text { (Poorly } \\
\text { soluble) }\end{array}$ & (Soluble) & $\begin{array}{l}\text { (Poorly } \\
\text { soluble) }\end{array}$ & $\begin{array}{l}\text { (Poorly } \\
\text { soluble) }\end{array}$ \\
\hline $\begin{array}{l}\text { Distribution coefficient } P \\
(\text { Log } P)\end{array}$ & 9.48 & 9.45 & 9.32 & 8.48 & 1.96 & 8.51 & 7.52 \\
\hline
\end{tabular}

\section{Absorption}

\begin{tabular}{llllllll}
$\begin{array}{l}\text { Caco2 permeability (Lop } \\
\text { Papp) }\end{array}$ & Caco2+ & Caco2- & Caco2- & Caco2+ & Caco2+ & Caco2- & Caco2- \\
\hline P-glycoprotein inhibitor & $\begin{array}{l}\text { Non- } \\
\text { inhibitor }\end{array}$ & $\begin{array}{l}\text { Non- } \\
\text { inhibitor }\end{array}$ & $\begin{array}{l}\text { Non- } \\
\text { inhibitor }\end{array}$ & $\begin{array}{l}\text { Non- } \\
\text { inhibitor }\end{array}$ & $\begin{array}{l}\text { Non- } \\
\text { inhibitor }\end{array}$ & $\begin{array}{l}\text { Non- } \\
\text { inhibitor }\end{array}$ & $\begin{array}{l}\text { Non- } \\
\text { inhibitor }\end{array}$ \\
\hline $\begin{array}{l}\text { P-glycoprotein substrate } \\
\text { Substrate }\end{array}$ & Substrate & Substrate & Substrate & $\begin{array}{l}\text { Non- } \\
\text { substrate }\end{array}$ & $\begin{array}{l}\text { Non- } \\
\text { substrate }\end{array}$ & $\begin{array}{l}\text { Non- } \\
\text { substrate }\end{array}$ \\
$\begin{array}{l}\text { Human Intestinal } \\
\text { absorption }(\mathrm{HIA})\end{array}$ & HIA- & HIA- & HIA- & HIA- & HIA+ & HIA- & HIA-
\end{tabular}

\section{Distribution}

\begin{tabular}{|c|c|c|c|c|c|c|c|}
\hline $\begin{array}{l}\text { Plasma Protein Binding } \\
\text { (PPB) }\end{array}$ & PPB- & PPB- & PPB- & PPB- & PPB- & PPB- & PPB- \\
\hline $\begin{array}{l}\text { Blood Brain Barrier } \\
\text { Permeability (BBB) }\end{array}$ & BBB- & BBB+ & BBB- & BBB- & BBB- & BBB- & BBB- \\
\hline
\end{tabular}

\section{Metabolism}

\begin{tabular}{|c|c|c|c|c|c|c|c|}
\hline CYP1A2 substrate & $\begin{array}{l}\text { Non- } \\
\text { Substrate }\end{array}$ & $\begin{array}{l}\text { Non- } \\
\text { Substrate }\end{array}$ & $\begin{array}{l}\text { Non- } \\
\text { Substrate }\end{array}$ & $\begin{array}{l}\text { Non- } \\
\text { Substrate }\end{array}$ & $\begin{array}{l}\text { Non- } \\
\text { Substrate }\end{array}$ & $\begin{array}{l}\text { Non- } \\
\text { Substrate }\end{array}$ & $\begin{array}{l}\text { Non- } \\
\text { Substrate }\end{array}$ \\
\hline CYP3A4 substrate & $\begin{array}{l}\text { Non- } \\
\text { Substrate }\end{array}$ & $\begin{array}{l}\text { Non- } \\
\text { Substrate }\end{array}$ & $\begin{array}{l}\text { Non- } \\
\text { Substrate }\end{array}$ & $\begin{array}{l}\text { Non- } \\
\text { Substrate }\end{array}$ & $\begin{array}{l}\text { Non- } \\
\text { Substrate }\end{array}$ & $\begin{array}{l}\text { Non- } \\
\text { Substrate }\end{array}$ & $\begin{array}{l}\text { Non- } \\
\text { Substrate }\end{array}$ \\
\hline CYP2C9 substrate & $\begin{array}{l}\text { Non- } \\
\text { Substrate }\end{array}$ & $\begin{array}{l}\text { Non- } \\
\text { Substrate }\end{array}$ & $\begin{array}{l}\text { Non- } \\
\text { Substrate }\end{array}$ & $\begin{array}{l}\text { Non- } \\
\text { Substrate }\end{array}$ & $\begin{array}{l}\text { Non- } \\
\text { Substrate }\end{array}$ & $\begin{array}{l}\text { Non- } \\
\text { Substrate }\end{array}$ & $\begin{array}{l}\text { Non- } \\
\text { Substrate }\end{array}$ \\
\hline CYP2C19 substrate & $\begin{array}{l}\text { Non- } \\
\text { Substrate }\end{array}$ & $\begin{array}{l}\text { Non- } \\
\text { Substrate }\end{array}$ & $\begin{array}{l}\text { Non- } \\
\text { Substrate }\end{array}$ & $\begin{array}{l}\text { Non- } \\
\text { Substrate }\end{array}$ & $\begin{array}{l}\text { Non- } \\
\text { Substrate }\end{array}$ & $\begin{array}{l}\text { Non- } \\
\text { Substrate }\end{array}$ & $\begin{array}{l}\text { Non- } \\
\text { Substrate }\end{array}$ \\
\hline CYP2D6 substrate & $\begin{array}{l}\text { Non- } \\
\text { Substrate }\end{array}$ & $\begin{array}{l}\text { Non- } \\
\text { Substrate }\end{array}$ & $\begin{array}{l}\text { Non- } \\
\text { Substrate }\end{array}$ & $\begin{array}{l}\text { Non- } \\
\text { Substrate }\end{array}$ & $\begin{array}{l}\text { Non- } \\
\text { Substrate }\end{array}$ & $\begin{array}{l}\text { Non- } \\
\text { Substrate }\end{array}$ & $\begin{array}{l}\text { Non- } \\
\text { Substrate }\end{array}$ \\
\hline CYP1A2 inhibitor & $\begin{array}{l}\text { Non- } \\
\text { Inhibitor }\end{array}$ & $\begin{array}{l}\text { Non- } \\
\text { Inhibitor }\end{array}$ & $\begin{array}{l}\text { Non- } \\
\text { Inhibitor }\end{array}$ & $\begin{array}{l}\text { Non- } \\
\text { Inhibitor }\end{array}$ & Inhibitor & $\begin{array}{l}\text { Non- } \\
\text { Inhibitor }\end{array}$ & $\begin{array}{l}\text { Non- } \\
\text { Inhibitor }\end{array}$ \\
\hline CYP23A4 inhibitor & $\begin{array}{l}\text { Non- } \\
\text { Inhibitor }\end{array}$ & $\begin{array}{l}\text { Non- } \\
\text { Inhibitor }\end{array}$ & $\begin{array}{l}\text { Non- } \\
\text { Inhibitor }\end{array}$ & Inhibitor & Inhibitor & $\begin{array}{l}\text { Non- } \\
\text { Inhibitor }\end{array}$ & $\begin{array}{l}\text { Non- } \\
\text { Inhibitor }\end{array}$ \\
\hline CYP2C9 inhibitor & $\begin{array}{l}\text { Non- } \\
\text { Inhibitor }\end{array}$ & $\begin{array}{l}\text { Non- } \\
\text { Inhibitor }\end{array}$ & $\begin{array}{l}\text { Non- } \\
\text { Inhibitor }\end{array}$ & $\begin{array}{l}\text { Non- } \\
\text { Inhibitor }\end{array}$ & Inhibitor & $\begin{array}{l}\text { Non- } \\
\text { Inhibitor }\end{array}$ & $\begin{array}{l}\text { Non- } \\
\text { Inhibitor }\end{array}$ \\
\hline CYP2C19 inhibitor & $\begin{array}{l}\text { Non- } \\
\text { Inhibitor }\end{array}$ & $\begin{array}{l}\text { Non- } \\
\text { Inhibitor }\end{array}$ & $\begin{array}{l}\text { Non- } \\
\text { Inhibitor }\end{array}$ & $\begin{array}{l}\text { Non- } \\
\text { Inhibitor }\end{array}$ & $\begin{array}{l}\text { Non- } \\
\text { Inhibitor }\end{array}$ & $\begin{array}{l}\text { Non- } \\
\text { Inhibitor }\end{array}$ & $\begin{array}{l}\text { Non- } \\
\text { Inhibitor }\end{array}$ \\
\hline CYP2D6 inhibitor & $\begin{array}{l}\text { Non- } \\
\text { Inhibitor }\end{array}$ & $\begin{array}{l}\text { Non- } \\
\text { Inhibitor }\end{array}$ & $\begin{array}{l}\text { Non- } \\
\text { Inhibitor }\end{array}$ & $\begin{array}{l}\text { Non- } \\
\text { Inhibitor }\end{array}$ & Inhibitor & $\begin{array}{l}\text { Non- } \\
\text { Inhibitor }\end{array}$ & $\begin{array}{l}\text { Non- } \\
\text { Inhibitor }\end{array}$ \\
\hline
\end{tabular}




\section{Toxicity}

\begin{tabular}{llllllll} 
heRG Blockers & $\begin{array}{l}\text { Non- } \\
\text { blockers }\end{array}$ & $\begin{array}{l}\text { Non- } \\
\text { blockers }\end{array}$ & $\begin{array}{l}\text { Non- } \\
\text { blockers }\end{array}$ & $\begin{array}{l}\text { Non- } \\
\text { blockers }\end{array}$ & $\begin{array}{l}\text { Non- } \\
\text { blockers }\end{array}$ & $\begin{array}{l}\text { Non- } \\
\text { blockers }\end{array}$ & $\begin{array}{l}\text { Non- } \\
\text { blockers }\end{array}$ \\
$\begin{array}{l}\text { Human hepatotoxicity (H- } \\
\text { HT) }\end{array}$ & HHT- & HHT- & HHT- & HHT- & HHT- & HHT- & HHT- \\
\hline AMES mutagenicity & Ames- & Ames- & Ames- & Ames- & Ames- & Ames- & Ames- \\
\hline Skin Sensitization, (r)LLNA & $\begin{array}{l}\text { Non- } \\
\text { sensitizer }\end{array}$ & $\begin{array}{l}\text { Non- } \\
\text { sensitizer }\end{array}$ & $\begin{array}{l}\text { Non- } \\
\text { sensitizer }\end{array}$ & $\begin{array}{l}\text { Non- } \\
\text { sensitizer }\end{array}$ & $\begin{array}{l}\text { Non- } \\
\text { sensitizer }\end{array}$ & $\begin{array}{l}\text { Non- } \\
\text { sensitizer }\end{array}$ & $\begin{array}{l}\text { Non- } \\
\text { sensitizer }\end{array}$ \\
$\begin{array}{l}\text { Drug Induced Liver Injury } \\
\text { (DILI) }\end{array}$ & DILI- & DILI- & DILI- & DILI+ & DILI+ & DILI- & DILI- \\
\hline
\end{tabular}

\section{Molecular Dynamic}

To evaluate the dynamics behavior of macromolecules at the molecular and atomic levels, all protein-ligand complexes were examined using MD simulations. From the docking results, compound $\mathbf{1 4 9}$ was observed to have the strongest affinity with $\mathrm{E}$, NS3/NS2B, NS5 methyltransferase, and NS5 RdRp. To investigate the dynamic behavior of the docking result, the docked complexes of 149 against E, NS3/NS2B, NS5 methyltransferase, and NS5 protein were subjected through MD simulation. The system can be monitored using root-mean-square deviation (RMSD) that gives information equilibration on structural conformation throughout the simulation. If fluctuations happen towards the end of the simulation and the changes are larger than $3 \AA$, it indicates that the protein undergoes a large conformational change, and the ligand is not stable in the binding pocket of the protein during the simulations.

The relative fluctuation in the RMSD of Ca carbon atoms (Ca-RMSD) for 149 bound to 10KE protein (Fig. 9A) was observed for the first $42 \mathrm{~ns}$. Between $42-90 \mathrm{~ns}$, the RMSD of the 10KE protein slightly decreases while 149 shows some marginal increase with a small fluctuation at the end with an RMSD value of $0.75 \AA$. In the case of $2 F O M$ (Fig. 9B), the RMSD showed a marginal decrease for $5 \mathrm{~ns}$ followed by a slight fluctuation for $38 \mathrm{~ns}$. Then, the RMSD of 149 increases to $0.8 \AA$ and converges at the end of the simulation. Similarly, the RMSD of 1R6A (Fig. 9C) slightly fluctuate for the first 35 ns followed by fluctuation between 35 to 45 $\mathrm{ns}$ and continue to fluctuate marginally between 45 to $85 \mathrm{~ns}$. The RMSD starts to converge at $85 \mathrm{~ns}$ to the end of the simulation (RMSD: $0.4 \AA$ ). The RMSD for 3VWS (Fig. 9D) showed the most stable ligand-protein complex due to the shorter time taken to reach convergence. At first, the RMSD showed a marginal increase for 25 ns before it started to converge throughout the simulation (RMSD: $0.8 \AA$ ).

Root-mean-square fluctuation (RMSF) is useful to indicate the local changes along with the mobility of the protein during the simulation. In the case of 10KE (Fig. 10A), a higher fluctuation was observed at the $C$-terminus residues up to $3.6 \AA$. Residues Thr48, Lys128, and Ala50 were recognized as a binding residue for 10KE that showed lesser fluctuation. Unlike 149 complexed with 2FOM (Fig. 10B), N-terminus residues showed a higher fluctuation of up to 3.0 A. Residues 10-15 and 40-45 tend to show more fluctuation as compared to the binding site residues (Lys74, Leu76, Gly87, Val147, Asn152, and Ala166). In the case of NS5 methyltransferase (Fig. 10C), higher fluctuation was observed at the $C$-terminus residues up to $2.8 \AA$. The RMSF for residues 40 50, 100-105 and 165-170 tend to show high fluctuation as compared to active site residues of Leu20, Lys14, Asn18, Lys29, Phe25, Leu17. Compound 149 complexed with 3VWS (Fig. 10D) was observed to have a marginally higher fluctuation at the $N$-terminus and the fluctuation was minimal for binding site residue, so it showed higher stability during the simulation.

To understand the conformational evolution of the ligand, the torsional conformations of each rotatable bond in the ligand throughout the simulation run were calculated (Fig. 11). The angle of each bond was illustrated by the dartboard plots while the probability of the torsions as a function of angle were illustrated by the histograms. The dartboard plot was placed in the centre of the radial plot at the beginning of the simulation trajectories while radially outwards at the time evolution. The angular coordinate was the torsional angle while the radial coordinate was the torsion rotatable bond [63]. The relationship between the torsional angle changes and interactions are directional proportional. This relationship was discovered while combining with the results on interactions observed through the docking model (Fig. 6 and Fig. 11). The results for compound 149 in the binding pocket of envelope dengue protein (Fig. 6A and Fig. 11A) displayed torsional angle changes in bond $\mathbf{e}$ and $\mathbf{d}$, promoted by the hydrogen bond interaction between the hydroxyl group and residue Thr48. In a similar way, the torsional angle changes in bond $\mathbf{c}$ 
correspond to the hydrogen bond interaction between the hydroxyl group and residue Pro53. The torsional angle also changes in bond $\mathbf{b}$ corresponding to the $\pi-\pi$ interaction between the aromatic ring and residue Ala50. The dartboard plots and the bar charts showed that bond $\mathbf{c}$ is rigid while bonds $\mathbf{b}, \mathbf{d}$, and $\mathbf{e}$ were more flexible.

In Fig. 6B and Fig. 11B, ligand 149 in the binding cavity of NS3/NS2B dengue protein showed the torsional angle changes in bond $\mathbf{a}$ and $\mathbf{e}$ promoted by the hydrogen bond interaction between the hydroxyl group and residue Asn152, Lys74, Gly 87 and Val147. The torsional angle changes in bond $\mathbf{c}$ were promoted by the hydrophobic (salt-bridge) interaction between the hydroxyl group and residue Lys74. The torsional angles also change in bond $\mathbf{b}$ corresponding to the $\pi-\pi$ interaction between the aromatic ring and residues Ala166, Leu76, Lys74 and Gol202. The bar charts and dial plots showed that the bonds b and $\mathbf{c}$ were rigid while bond $\mathbf{a}$ and $\mathbf{e}$ are more flexible.

The torsional angle for compound 149 in the binding site of NS5 methyltransferase was shown in combination of Fig. 6C and Fig. 11C. The Torsional angle changes in bond e promotes the hydrogen bond interaction between the hydroxyl group and residue Ser150. The torsional angle changes in bond $\mathbf{c}$ and $\mathbf{d}$ were promoted by the hydrophobic interaction between the hydroxyl group and residues Lys22 and Lys29. The torsional angles also change in bond $\mathbf{b}$ correspond to the $\pi-\pi$ interaction between the aromatic ring and residue Phe25. From the bar charts and dial plots, bond $\mathbf{b}, \mathbf{d}$ and $\mathbf{e}$ were flexible compared to bond $\mathbf{c}$ which was more rigid.

Ligand 149 in the binding pocket of NS5 RdRp (Fig. 6D and Fig. 11D) showed torsional angle changes in bond a and $\mathbf{c}$ promoted by the hydrogen bond interaction between the hydroxyl group and residues Asn405 and Thr413. The torsional angles in the bond a corresponded to the hydrophobic interaction between hydroxyl group and residues Arg792. In addition, the torsional angle also changes in bond $\mathbf{b}$ promoted by the $\pi-\pi$ interaction between aromatic ring and residue Trp795. The dial plots and bar charts showed that the bonds $\mathbf{a}, \mathbf{b}$, and $\mathbf{c}$ are more flexible. It was shown that ligand $\mathbf{1 4 9}$ in the binding pocket of NS5 RdRp had more rotatable bonds which indicates that the molecule is flexible, and the complex is stable throughout the simulation.

To illustrate the stability of the selected ligand in the binding pocket of the proteins during the simulation, these six properties were analyzed: 1) root mean square deviation (RMSD) of a ligand concerning the reference confirmation; 2 ) radius of gyration ( $r$ Gyr) as an indicator of extendedness of a ligand; 3 ) intramolecular hydrogen bond (intra-HB) as the number of internal hydrogen bonds (HB) within a ligand molecule; 4) molecular surface area (MolSA) calculated with $1.4 \AA$ probe radius; 5) solvent accessible surface area (SASA) is the surface area of a biomolecule that is accessible to a solvent; 6 ) polar surface area (PSA) is a solvent accessible surface area in a molecule contributed only by oxygen and nitrogen atoms [62]. As shown in Fig. 12A, the RMSD value of compound 149 in the active site of envelope protein was below $1.5 \AA$. Striking fluctuation occurs at 20-30 ns and 45-100 ns. This could lead to instability of the ligand in the active site of the protein. The RMSD value for compound 149 in the active site of NS3/NS2B protein and NS5 methyltransferase (Fig. 12B and Fig. 12C) slightly fluctuates at the first 5 ns at 0.8-1.2 $\AA$, before it starts to stabilize at $0.8 \AA$ from $5-38 \mathrm{~ns}$ and the value was lower than $0.5 \AA$ after $38 \mathrm{~ns}$. For compound 149 in the binding site of NS5 methyltransferase, the RMSD value showed a marginal fluctuation for the first $35 \mathrm{~ns}$. The RMSD value showed presence of minor fluctuation throughout the remaining simulation run. The RMSD value of ligand $\mathbf{1 4 9}$ in the active site of NS5 RdRp (Fig. 12D) showed some fluctuations for the first $20 \mathrm{~ns}$ and then it starts to reach convergence after $20 \mathrm{~ns}$ at $1.2 \AA$.

The results of changes in the rGyr of ligand bound to the active site of the proteins are shown in Fig. 13. The rGyr value for the ligand compound 149 in the binding pocket of the envelope protein (Fig. 13A) was stable at 3.65-3.80 $\AA$ from 0 to $100 \mathrm{~ns}$. The rGyr value for compound 149 in the binding pocket of NS3/NS2B protein (Fig. 13B), NS5 methyltransferase protein (Fig. 13C), and NS5 RdRp protein (Fig. 13D) showed a constant value at 3.70-3.80 ̊ from 0 to $100 \mathrm{~ns}$. These constant values predicted a steady behaviour and compactness of the structure that exerts a great effect on the quality of the substrate binding to the active site.

The consistency of the ligand during the simulation run was also indicated by intraHB, MoISA, PSA, and SASA. The properties of MoISA and PSA for compound $\mathbf{1 4 9}$ with all targeted proteins produced a consistent value throughout the simulation run. This constant value discovered the consistency of the ligand in the binding pocket throughout the simulation run. Additionally, the solvent-accessible surface area (SASA) was also calculated. This analysis measured the surface area of a molecule accessible by a water molecule. An increase in SASA values from the initial pose indicates that the ligand was exiting the binding pocket or sticking out into water while decreasing value of SASA indicates that more of the molecule was buried in the protein. To pursue 
the stability of the ligand in the binding pocket of protein, lower scores of SASA are priority. According to Fig. 14A, the SASA analysis for ligand 149 in envelope protein showed a constant value at $180 \AA^{2}$ for the first 40 ns. However, the instability of the SASA value was observed from $40 \mathrm{~ns}$ to the end of the simulation run. The SASA analysis of compound 149 in NS3/NS2B (Fig. 14B) showed some fluctuation (100-200 $\AA^{2}$ ) for the first 40 ns but then it showed a decreasing score at $50 \AA^{2}$ until the end of the simulation run. The SASA value for ligand 149 in NS5 methyltransferase (Fig. 14C) showed a marginal decrease for the first $5 \mathrm{~ns}$. Then, it showed a constant value at 5 to $37 \mathrm{~ns}$. After that, the SASA value was observed to slightly fluctuate throughout the simulation at 180-240 $\AA^{2}$. For the ligand 149 in NS5 RdRp protein (Fig. 14D), the SASA analysis showed some fluctuations for the first 20 ns. After 20 ns, SASA was observed to form a steady behaviour at $30 \AA^{2}$ throughout the simulation process.

The comparison of the protein-ligand contacts from docking results and molecular dynamic simulation are important to predict the stability and the interactions in the binding site. Based on the docking result of compound 149 with envelope protein, the complex was stable due to H-bond interaction with residues Thr48 and Pro53, hydrophobic interaction with residue Lys128 and $\pi-$ $\pi$ interaction with residues Ala50, lle270 and Pro53. In comparison, the molecular dynamic simulation result (Fig. 15A and Fig. 16A) showed that this complex was able to maintain H-bond interaction with Asn18, Phe25 and Glu149 at 99\%, 70\% and 90\% of the simulation time respectively. The presence of interactions with new residues in the simulation run showed the instability of the compound 149 in the binding site of envelope protein. For the compound 149 in NS3/NS2B, the complex was stable due to Hbond with residues Asn152, Lys74, Val147 and Gly87, hydrophobic interaction with Lys74 and $\pi-\pi$ interaction with residues Ala166, Leu76, Lys74 and Ala166, while for the molecular dynamic analysis (Fig. 15B and Fig.16B), interaction with Lys74 was observed to maintain at $32 \%$ of the simulation run. In addition, the interaction with residues Asp75 (60\%), Leu149 (100\%) and Asn152 (20\%) was also present during the simulation run.

The docking result of complex 149 in NS5 methyltransferase showed the H-bond interaction with Ser150 and Pro152, hydrophobic interaction with Lys22 and Lys29 and $\pi-\pi$ interaction with Phe25 and Pro152. However, the interaction with residues Lys 22 and Lys 29 was only maintained for less than $10 \%$ of the simulation run (Fig. 15C and Fig. 16C). Interestingly, the presence of new interaction with active residues Lys14 (62\%), Asn18 (99\%), Glu149 (30\%) and Ser150 (10\%) was also observed. For the NS5 RdRp, docking results showed that compound 149 forms a H-bond interaction with residues Thr413 and Asn405, hydrophobic interaction with residue Arg792 and $\pi-\pi$ interaction with residue Trp795. In comparison with molecular dynamic simulation (Fig. 15D and Fig. 16D), the interaction with residues Asn405, Thr413, Trp795 and Arg792 was maintained at $<10 \%$, $20 \%, 48 \%, 100 \%$ of the simulation run respectively. In addition, new interaction with active residues Val411, Arg352, Ser796 and His801 was also observed.

Based on the RMSD and RMSF value, the complex of 149 with protein 3VWS was more stable due to the shorter time to reach convergence and minor fluctuation of the active residues during the simulation run. Throughout the simulation, protein-ligand interaction can be monitored. The stability of the specific interaction of the protein-ligand complex was recorded during the simulation. Based on the result, the complex 149 with $3 \mathrm{VWS}$ was stable as compared to other protein targets due to the ability to maintain the most number of interactions with active residues Asn405, Thr413, Trp795 and Arg792 during the simulation run. In addition, the six properties analysis to predict the stabilities of the selected ligand in the binding pocket also showed that it takes a shorter time to reach convergence. It shows that ligand $\mathbf{1 4 9}$ can interact well and it is stable in the binding site of the NS5 RdRp proteins.

\section{Conclusion}

The findings indicate that compound $\mathbf{1 4 9}$ has the most number of interactions and one of the best docking energy values with all the targeted proteins through the docking analysis. This compound, which belongs to the flavonoid derivatives, passed the Lipinski' rule and showed potential through ADMET analysis. Overall, all the ligands fit well in the binding site of the targeted protein through simulation run. Among these targeted proteins, the complex of 149 with 3 VWS was considered the most preferable and the most stable due to the shorter time taken to reach convergence and minor fluctuation of the active residues during the simulation. Compound 149 also interacts well with binding site residues Thr413, Asn405, Arg792, and Trp795 for more than $30 \%$ of the simulation time. This showed that the interaction of the complex was stable and could lead to prevent replication of the dengue virus.

Page 15/31 


\section{Declarations}

\section{Acknowledgment}

The authors would like to acknowledge Malaysia Ministry Higher of Education for the support through a research grant (FRGS), [UiTM600-RMI/FRGS 5/3 (0063/2016)]; [UiTM600-IRMI/FRGS 5/3 (111/2019)]; and research grant DUCS UiTM Selangor campus [DUCS600-UiTMSEL (P1. 5/4) -(001/2020)]. The first author would also like to thank UiTM and AuRIns for the excellent research facilities.

Funding Internal funds of the department supported the research

Conflict of interest The authors declare no competing interests

Availability of data and material N/A.

Code availability N/A.

Author's contributions NNA performed study and wrote manuscript; SIAB conceived the idea and guide and check the manuscript.

\section{References}

1. Gubler DJ (1998) Dengue and dengue hemorrhagic fever. Clinical Microbiology Review. 11(3) 480-496.

2. Ul Qamar MT, Maryam A, Muneer I, Xing F, Ali AU, Ahmed Khan F, Anwar F, Geesi MH, Khalid RR, Abdul Rauf S, Siddiqi AR (2019) Computational screening of medicinal plant phytochemicals to discover potent pan-serotype inhibitors against dengue virus. Scientific reports. 9:1433. https://doi.org/10.1038/s41598-018- 38450-1

3. Burke DS, Nisalak A, Johnson DE, Scott RM (1988) A prospective study of dengue infections in Bangkok. Am. J. Trop. Med. Hyg. 38:172-180.

4. Sangkawibha N, Rojanasuphot S, Ahandrik S, Viriyapongse S, Jatanasen S, Salitul V, Phanthumachinda B, Halstead SB (1984) Risk factors in dengue shock syndrome: A prospective epidemiologic study in Rayong, Thailand. I. The 1980 outbreak. Am. J. Epidemiol. 120: 653-669.

5. Salam KA, Akimitsu N (2013) Hepatitis C Virus NS3 Inhibitors: Current and Future Perspectives. BioMed Res. Int. 9: 467869. https://doi.org/10.1155/2013/467869

6. Ul Qamar M T, Mumtaz A, Ashfaq UA, Adeel MM Tabeer F (2014) Potential of plant alkaloids as dengue NS3 protease inhibitors: Molecular docking and simulation approach. Bangladesh J. Pharmacol. 9: 262267. https://doi.org/10.3329/bjp.v9i3.18555

7. Cleaves GR, Dubin DT (1979) Methylation status of intracellular dengue type 240 S RNA. Virology. 96(1): 159-165.

8. Malet H, Massé N, Selisko B, Romette JL, Alvarez K, Guillemot JC, Tolou H, Yap TL, Vasudevan S, Lescar J, Canard B (2008) The flavivirus polymerase as a target for drug discovery. Antiviral Res. 80: 23-35.

9. Mukhtar M, Arshad M, Ahmad M, Pomerantz RJ, Wigdahl B Parveen Z (2008) Antiviral potentials of medicinal plants. Virus Research. 131: 111-120.

10. Lee AT, Azimahtol HL, Tan AN (2003) Styryl pyrone derivative (SPD) induces apoptosis in a caspase-7- dependent manner in the human breast cancer cell line MCF-7. Cancer cell Int. 4;3(1): 16.

11. Li LK, Ali-Saeed R, Kaid FA, Ali AM, and Alabsi AM (2016) Goniothalamin induces cell cycle arrest and apoptosis in H400 human oral squamous cell carcinoma: A caspase-dependent mitochondrial-mediated pathway with downregulation of NF-к $\beta$. 
Arch. Oral Biol. 64: 28-38.

12. Wiart C (2007) Goniothalamus species: a source of drugs for the treatment of cancers and bacterial infections? EvidenceBased Complementary and Alternative Medicine. 4: 299-311.

13. Cao SG, Wu XH, Sim KY, Tan BKH, Pereira JT, Goh SH (1998) Styryl-lactone derivatives, and alkaloids from Goniothalamus borneensis (Annonaceae). Tetrahedron. 5: 2143-2148.

14. Claire L, Melodie B, Karren DB, Anthony RC, Frederic M, Vanida C, Rohan, AD (2013) Pyridocoumarine, aristolactam and aporphine alkaloids from the Australian rainforest plant Goniothalamus australis. Phytochemistry, 86: 121-126.

15. Ichino C, Soonthornchareonnon N, Chuakal W, Kiyohara H, Ishiyama A, Sekiguchi H, Namatame M, Otoguro K, Omura S, Yamada H (2006) Screening of Thai medicinal plant extracts and their active constituents for in vitro antimalarial activity. Phytotherapy Research. 20: 307-309.

16. Prawat U, Chaimanee S, Butsuri A, Salae AW, Tuntiwachwuttikul P (2012) Bioactive styryl lactone, two new naphthoquinones and one new styryllactone, and other constituents from Goniothalamus scortechinii. Phytochemistry Letters. 5: 529-534.

17. Zandi K, Teoh B-T, Sam S-S, Wong P-F, Mustafa M, Abu Bakar S (2011) Antiviral activity of four types of bioflavonoid against dengue virus type 2. Virology Journal, 8(1):560.

18. Wahab NZA, Ibrahim N, Kamarudin MKA, Lananan F, Juahir H, Ghazali A, Ireana Yusra, AF (2018) Cytotoxicity and antiviral activity if Annona Muricata aqueous leaves extract against dengue virus type 2. J. Fundam. Appl. Sci. 10(1S): 580-589.

19. Hassandarvish P, Rothan HA, Rezaei S, Yusof R, Abubakar S, Zandi K (2016) In silico on baicalein and baicalin as inhibitors of dengue virus replication. Royal Society of Chemistry. 6:31235-31247.

20. Balajee R, Srinivasadesikan V, Sakthivadivel M, Gunasekaran P (2016) In Silico Screening, Alanine Mutation and DFT Approaches for Identification of NS2B/NS3 Protease Inhibitors. Biochemistry Research International. 13.

21. Kittisak L, Chaweewan K, Vichien J, Boonchoo S, Samphan W (2006) Flavones with free radical scavenging activity from Goniothalamus tenuifolius. Archives of Pharmacal Research. 29(3): 199-202.

22. Liege CS, Geraldo OS, Nirlei S, Fabiano B, Valquiria, LB (2014) 3-O-Methylquercetin from organic Nicotiana tabacum L. trichomes: Influence of the variety, cultivation, and extraction parameters. Industrial Crops and Products. 55: 56-62.

23. Johansson M, Brookes AJ, Jans DA, Vasudevan SG (2001) A small region of the dengue virus-encoded RNA- dependent RNA polymerase, NS5, confers interaction with both the nuclear transport receptor importin-b and the viral helicase, NS3. J Gen Virol. 82: 735-745.

24. Geiss BJ, Stahla H, Hannah AM, Gari HH, Keenan SM (2009) Focus on flaviviruses: current and future drug targets. Future Med. Chem.1(2): 327.

25. Noble CG, Chen YL, Dong H, Gu F, Lim SP, Schul W, Wang QY, Shi, PY (2010) Strategies for Development of Dengue Virus Inhibitors. Antiviral Research. 85(3) 450-462.

26. Wu G, Robertson DH, Brooks CL Vieth M (2003) Detailed analysis of grid-based molecular docking: A case study of CDOCKER -A CHARMm-based MD docking algorithm. Journal of Computational Chemistry. 24: 1549-1562.

27. Bihud N V, Rasol NE, Imran S, Awang K, Ahmad FB, Mai C-W, Ismail NH (2019) Goniolanceolatins A- H, Cytotoxic Bisstyryllactones from Goniothalamus lanceolatus. Journal of Natural Products.

28. Rasol NE, Ahmad FB, Mai CW, Bihud NV, Abdullah F, Awang K, Ismail NH (2018) Natural Product Communication. 13(12): 1575-1578.

Page 17/31 
29. Bermejo A, BlaÂ zquez MA, Rao KS, Cortes D (1998) Styryl-pyrones from Goniothalamus arvensis stem bark. Phytochemistry. 47: 1375-1380.

30. Aslam MS, Ahmad MS, Mamat AS, Ahmad MZ (2016) Goniothalamus: Phytochemical and Ethnobotanical Review. Recent Advances in Biology and Medicine. 2: 34-47.

31. Ahmad FB, Tukol WA, Omar S, Sharif AM (1991) 5-Acetyl goniothalamin, a styryl dihydropyrone from Goniothalamus uvaroides. Phytochemistry. 30: 2430-2431.

32. Goh SH, Ee GCL, Chuah CH, Mak TCW (1995) 5b-Hydroxygoniothalamin, a styryl-pyrone derivative from Goniothalamus dolichocarpus (Annonaceae). Nat. Prod. Lett. 5: 255-259.

33. Hasan CM, Mia MY, Rashid MA, Connolly JD (1994) 5-Acetoxyisogoniothalamin oxide, an epoxy styryl-lactone from Goniothalamus sesquipedalis. Phytochemistry. 37: 1763-1764.

34. Zhang J, Gao G, Chen L, Deng X, Li J, Yu Y, Zhang D, Li F, Zhang M, Zhao Q, Huang C (2013) Cheliensisin A Inhibits EGFInduced Cell Transformation with Stabilization of p53 Protein Via a Hydrogen Peroxide/Chk1-Dependent Axis. Cancer Prevention Research. 6(9):949-58.

35. Lekphrom R, Kanokmedhakul S, Kanokmedhakul K (2009) Bioactive styryllactones and alkaloid from flowers of Goniothalamus laoticus. Journal of Ethnopharmacology. 125: 47-50.

36. Wu Y-C, Duh C-Y, Chang F-R, Chang G-Y, Wang S-K, Chang J-J, Lee K-H (1991) The Crystal Structure and Cytotoxicity of Goniodiol-7-monoacetate from Goniothalamus amuyon. Journal of Natural Products, 54(4): 1077-1081.

37. Choo CY, Abdullah N, Diederich M (2014) Cytotoxic activity and mechanism of action of metabolites from the Goniothalamus genus. Phytochemistry Reviews, 13(4): 835-851. doi:10.1007/s11101-014-9372-2

38. Fang XP, Anderson JE, Chang CJ, Mclaughlin JL, Fanwick PE (1991) Two New Styryl Lactones, 9- Deoxygoniopypyrone and 7-epi-Goniofufurone, from Goniothalamus giganteus. Journal of Natural Product. 54(4): 1034-1043.

39. Bermejo A, Lora MJ, BlaÂ zquez MA, Rao KS, Cortes D, Zafra-Polo MC (1995) Goniotharvensin, a novel styryl-lactone from the stem bark of Goniothalamus arvensis. Nat. Prod. Lett. 7: 117-122.

40. Bermejo A, BlaÂ zquez MA, Serrano A, Zafra-Polo MC, Cortes D (1997) Preparation of 7-alkoxylated furano-pyrones: semi-

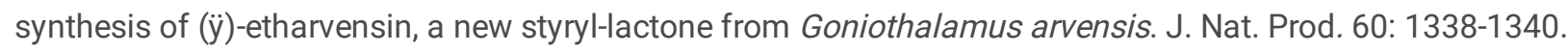

41. El-Zayat AE, Ferrigni NR, McCloud TG, McKenzie AT, Byrn SR, Cassady JM, Chang CJ, McLaughlin JL (1985) Goniothalenol: a novel bioactive, tetrahydrofurano- 2-pyrone from Goniothalamus giganteus (Annonaceae). Tetrahedron Lett. 26: 955-956.

42. De Fatima A, Modolo L, Conegero L, Pilli R, Ferreira C, Kohn L, de Carvalho J (2006) Styryl Lactones and Their Derivatives: Biological Activities, Mechanisms of Action and Potential Leads for Drug Design. Current Medicinal Chemistry, 13(28): 33713384. doi:10.2174/092986706779010298

43. Fang XP, Anderson JE, Chang CJ, Fanwick PE, McLaughin JL (1990) Novel bioactive styryl-lactones: goniofufurone, goniopypyrone and 8-acetylgoniotriol from Goniothalamus giganteus (Annonaceae). X-Ray molecular structure of goniofufurone and of goniopypyrone. J. Chem. Soc. Perkin Trans. 1: 1655-1661.

44. Cirrincione G, Diana P (2008) Goniothalamus: Eight-membered and larger Heterocyclic Rings and their Fused Derivatives, Other Seven-membered Rings. Comprehensive Heterocyclic Chemistry III.

45. Fang XP, Anderson JE, Chang CJ, McLaughlin JL, Fanwick PE (1991a) Two new styryl-lactones, 9- deoxygoniopypyrone and 7-epi-goniofufurone, from Goniothalamus giganteus. J. Nat. Prod. 54: 1034-1043. 
46. Fang XP, Anderson JE, Chang CJ, McLaughlin JL (1991b) Three new bioactive styryl-lactones from Goniothalamus giganteus (Annonaceae). Tetrahedron. 47: 9751-9758.

47. Fang XP, Anderson JE, Qiu XX, Kozlowski JF, Chang CJ, McLaughlin JL (1993) Gonioheptolides A and B: novel eightmembered ring lactones from Goniothalamus giganteus (Annonaceae). Tetrahedron. 49: 1563- Cos P, Ying L, Calomme, Hu JP, Cimanga K, Van Poel B, Pieters L, Vlietinck AJ, Vanden Berghe D (1998)

48. Structure-activity Relationship and Classification of Flavanoids as Inhibitors of Xanthine Oxidase and Superoxide Scavengers. Journal of Natural Product. 61(1): 71-6.

49. Iqbal E, Lim LBL, Salim KA, Faizi S, Ahmed A, Mohamed AJ (2018) Isolation, and characterization of aristolactam alkaloids from the stem bark of Goniothalamus velutinus (Airy Shaw) and their biological activities. Journal of King Saud University Science. 30(1): 41-48.

50. Dictionary of Natural Product (DNP). CRC Press, Taylor \& Francis Group, an Informa Group company. (2020). https://dnp.chemnetbase.com/faces/chemical/ChemicalSearch.xhtml

51. Zhou Z, Khaliq M, Suk JE, Patkar C, Li L, Kuhn RJ, Post CB. (2008) Antiviral compounds discovered by virtual screening of small molecule libraries against dengue virus E protein. ACS Chem Biol. 3: 765-75. Lim SP, Wang QY, Noble CG, Chen YL, Dong H, Zou B, Yokokawa F, Nilar S, Smith P, Beer D, Lescar J, Shi PY (2013a) Ten years of dengue drug discovery: progress and prospects. Antiviral Res. 100: 500-519, http://dx.doi.org/10.1016/j.antiviral.2013.09.013

53. Deng J, Li N, Liu H, Zuo Z, Liew OW, Xu W, Chen G, Tong X, Tang W, Zhu J, Zuo J, Jiang H, Yang CG, Li J, Zhu W (2012) Discovery of novel small molecule inhibitors of dengue viral NS2B-NS3 protease using virtual screening and scaffold hopping. Journal of Medicinal Chemistry. 26;55(14): 6278-93.

54. Yang CC, Hu HS, Wu RH, Wu SH, Lee SJ, Jiang WT, Chern JH, Huang ZS, Wu HN, Chang CM, Yueh A (2014) A novel dengue virus inhibitor, BP13944, discovered by high throughput screening with dengue virus replicon cells select for resistance in the viral NS2B/NS3 protease. Antimicrob Agents Chemother. 58: 110-9.

55. Steuer C, Gege C, Fischl W, Heinonen KH, Bartenschlager R, Klein CD (2011) Synthesis and biological evaluation of aketoamides as inhibitors of the Dengue virus protease with antiviral activity in cell-culture. Bioorg Med Chem. 19: 4067-74.

56. PoDENVinec M, Lim SP, Schmidt T, Scarsi M, Wen D, Sonntag L. S, Sans Chagrin P, Shenkin PS, and Schwede T (2010) Novel Inhibitors of Dengue Virus Methyltransferase: Discovery by in Vitro-Driven Virtual Screening on Desktop Computer Grid. J. Med.Chem. 53: 1483-1495.

57. Lim SP, Noble CG, Shi PY (2015) The dengue virus NS5 protein as a target for drug discovery. Antiviral Res. 119: 57-67, http://dx.doi.org/10.1016/j.antiviral.2015.04.010

58. Malet H, Massé N, Selisko B, Romette JL, Alvarez K, Guillemot JC, Tolou H, Yap TL, Vasudevan S, Lescar J, Canard B (2008) The flavivirus polymerase as a target for drug discovery. Antiviral Res. 80: 23-35.

59. Caillet-Saguy C, Lim SP, Shi PY, Lescar J, Bressanelli S (2014) Polymerases of hepatitis C viruses and flaviviruses: structural and mechanistic insights and drug development. Antiviral Res. 105: 8-16, http://dx.doi.org/10.1016/j.antiviral.2014.02.006

60. Abd Wahab NZ, Ibrahim N (2020) In vitro study, Antiviral Activity of Styryl pyrone Derivative Against Dengue Virus Type 2. Asian Journal of Plant Sciences, 19: 438-442.

61. Zhang Y, Zhang W, Ogata S, Clements D, Strauss JH, Baker TS, Rossmann MG (2004) Conformational Changes of the Flavivirus E Glycoprotein. Structure, 12(9): 1607-1618.

62. Raj U, Kumar H, Gupta S, Varadwaj P (2015) Novel DOT1L receptor natural inhibitors involved in mixed lineage leukemia: a virtual screening, molecular docking, and dynamics simulation study. Asian Pacific J. Cancer Prev. 16 (9): 3817-3

Page 19/31 
63. Zhang J, Liu X, Wang SQ, Liu GY, Xu WR, Cheng XC, Wang RL (2017) Identification of dual ligands targeting angiotensin II type 1 receptor and peroxisome proliferator-activated receptor-y by core hopping of telmisartan. J. Biomol. Struct. Dyn. 35 (12): 2665-2680.

\section{Figures}
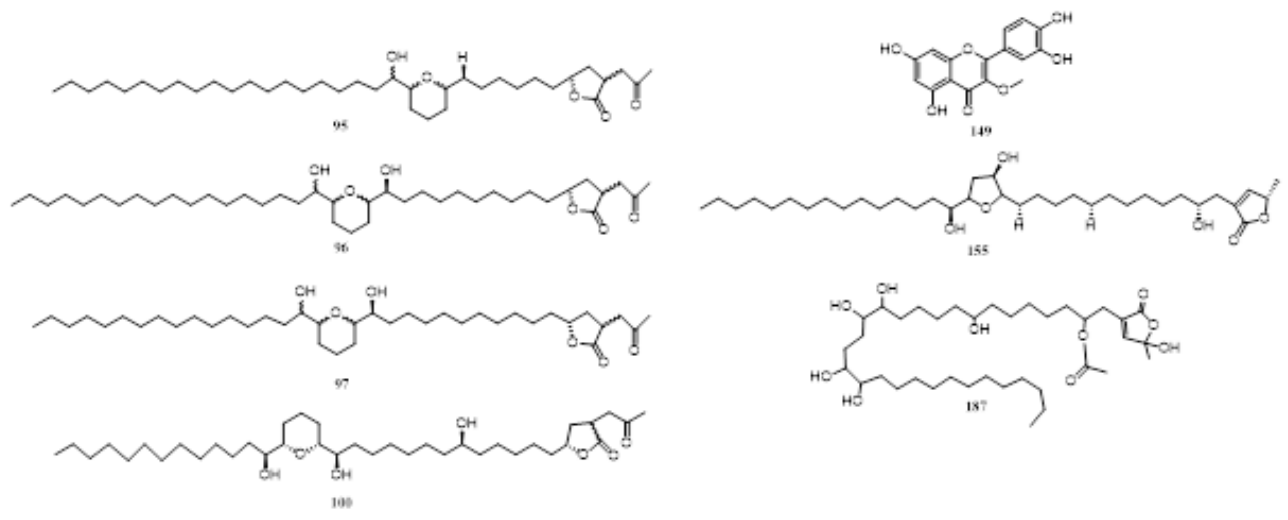

\section{Figure 1}

2D Chemical structure of top-ranked inhibitors. (95) Gigantetrocinone (96) Gonioneninone (97) Xylomaticinone (100) Annomontacinone (149) 5,7,3',4'-tetrahydroxy-3-methoxyflavone (155) Donnaienin and (187) Epidonnaienin
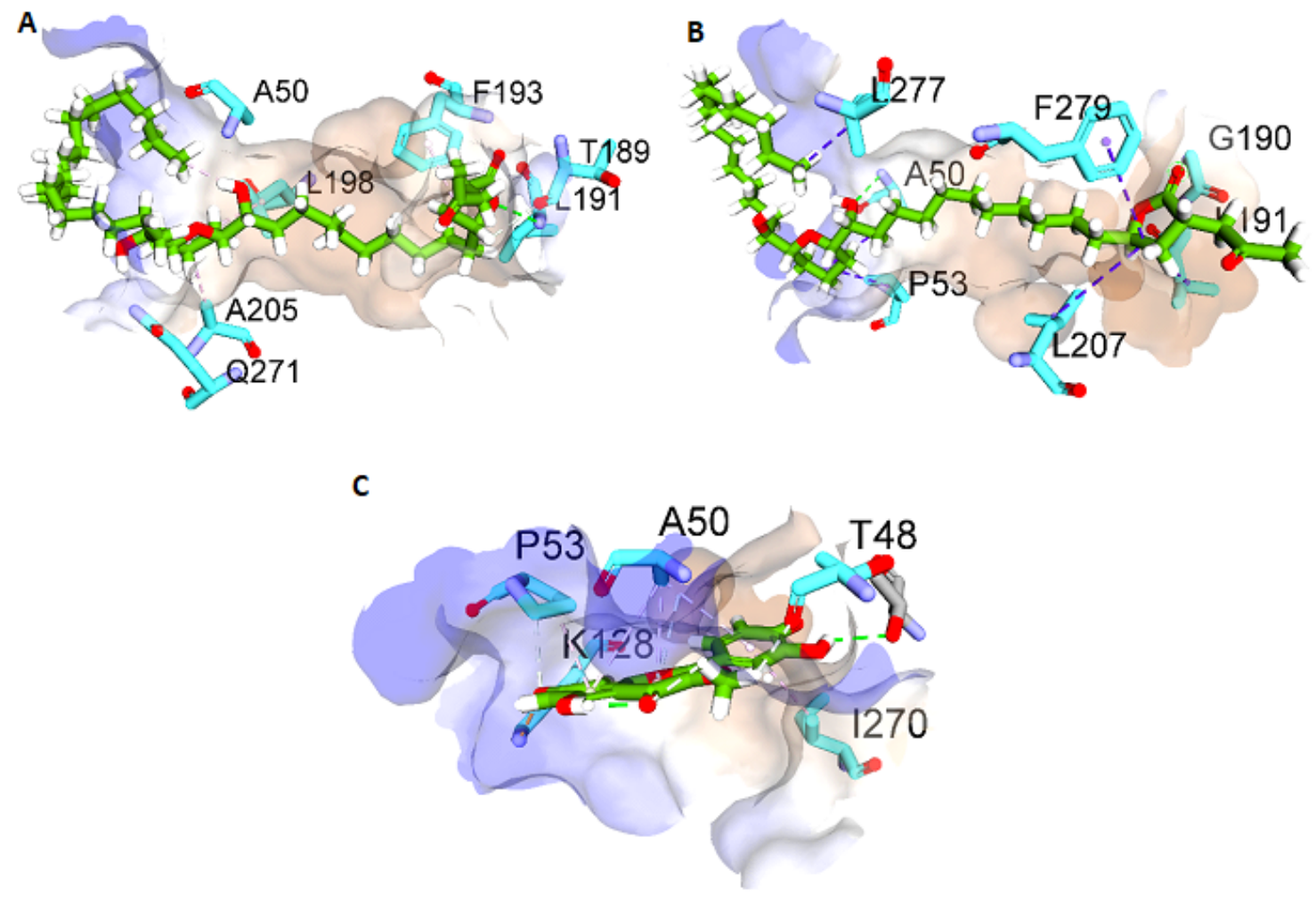

\section{Figure 2}

(A) 3D Interaction of 96 with E DENV protein (PDB 1OKE); (B) 3D Interaction of 97 with E DENV protein (PDB 1OKE); (C) 3D Interaction of 149 with E DENV protein (PDB 1OKE). 

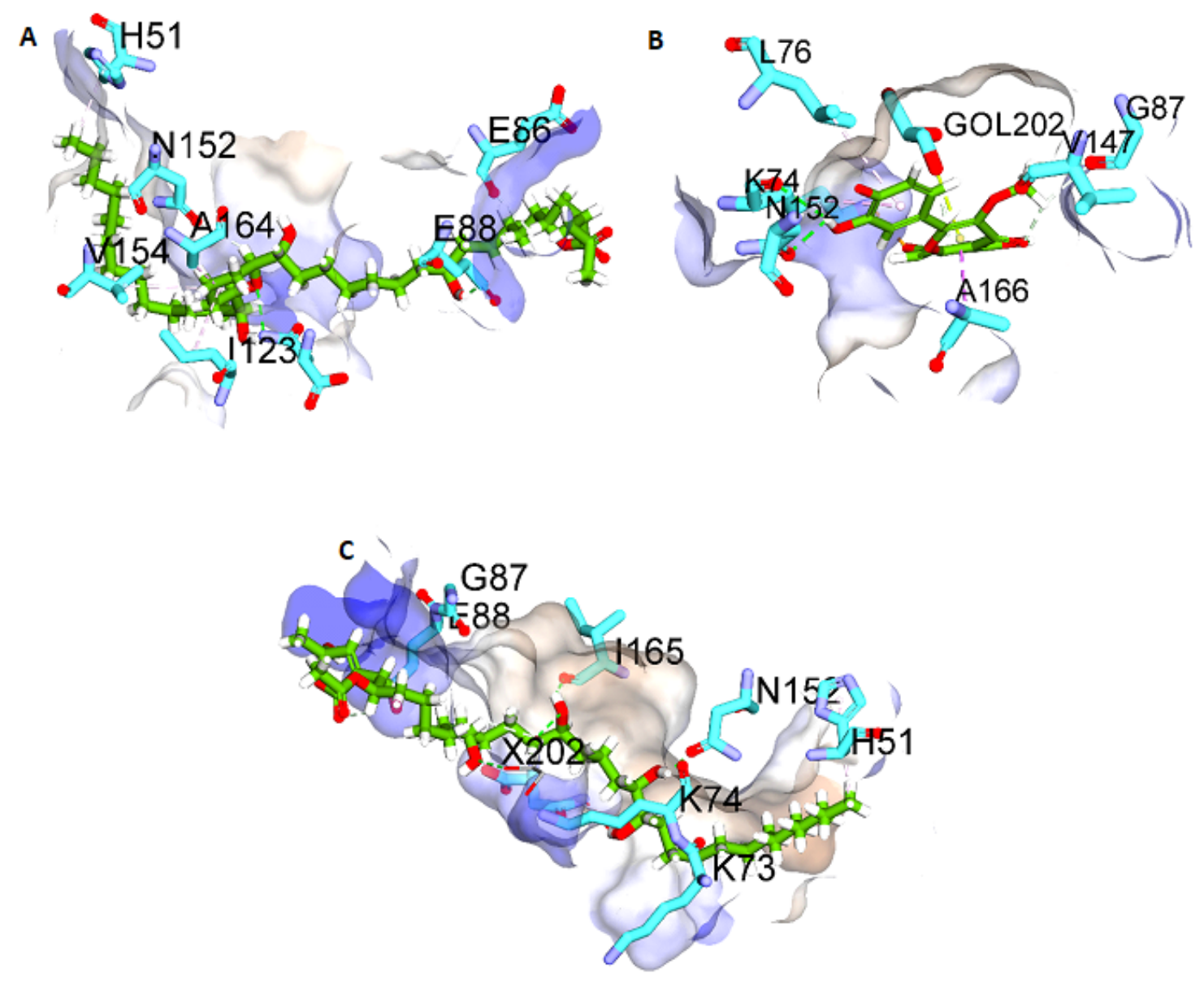

\section{Figure 3}

(A) 3D Interaction of 100 with NS3/NS2B DENV protein (PDB 2FOM); (B) 3D Interaction of 149 with NS3/NS2B DENV protein (PDB 2FOM); (C) 3D Interaction of 155 with NS3/NS2B DENV protein (PDB 2FOM). 


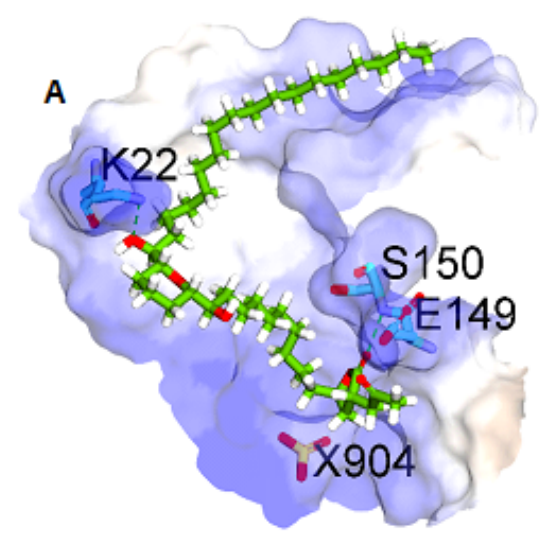

B
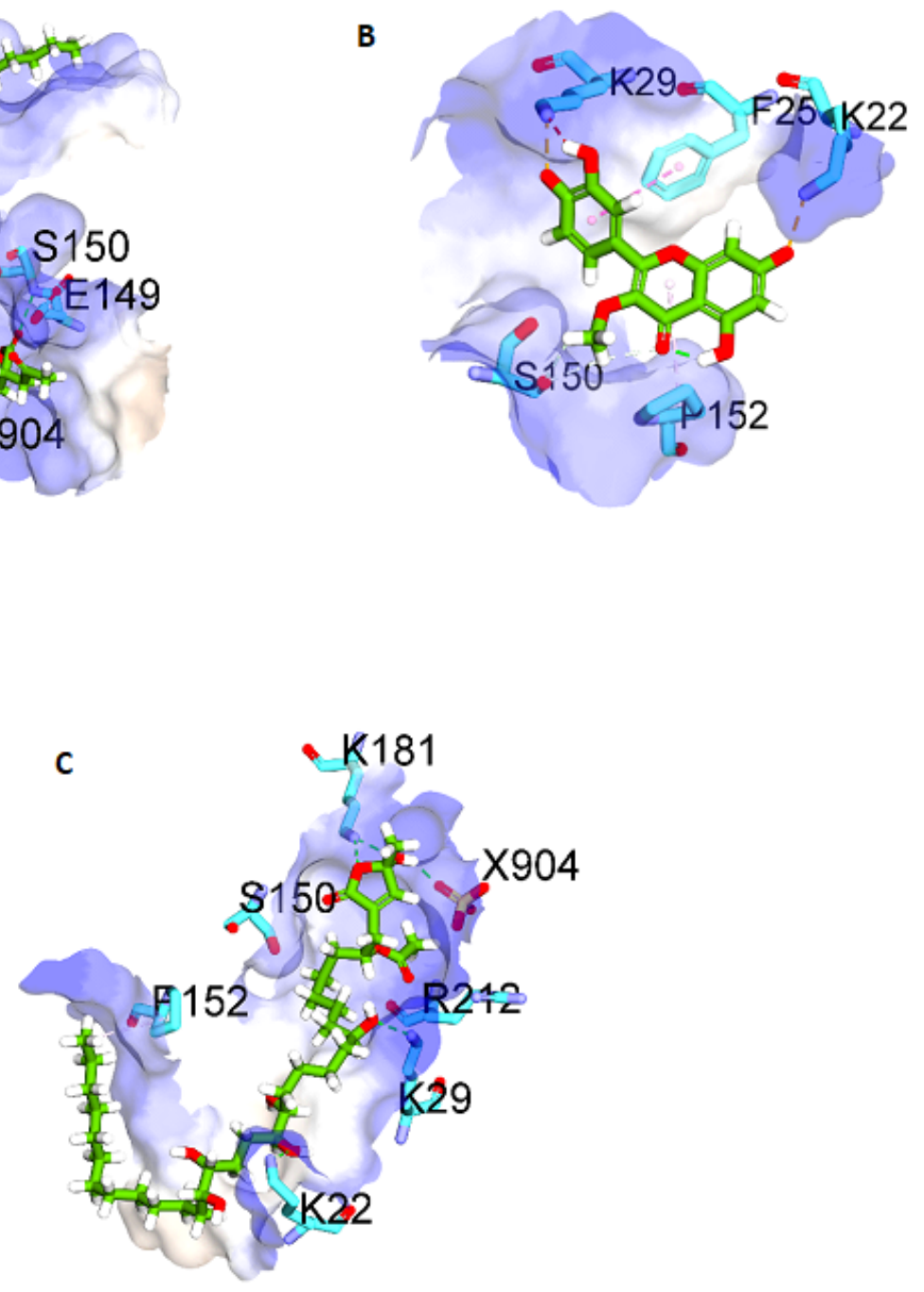

Figure 4

(A) 3D Interaction of 96 with NS5 Methyltransferase DENV protein (PDB 1R6A); (B) 3D Interaction of 149 with NS5 Methyltransferase DENV protein (PDB 1R6A); (C) 3D Interaction of 187 NS5 Methyltransferase DENV protein (PDB 1R6A). 
A

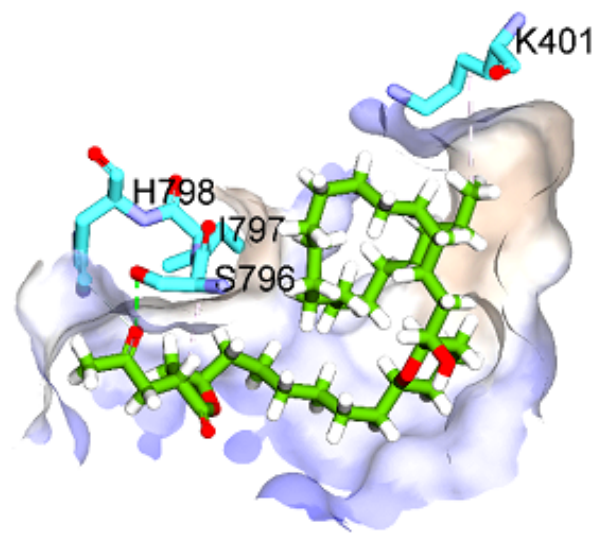

B

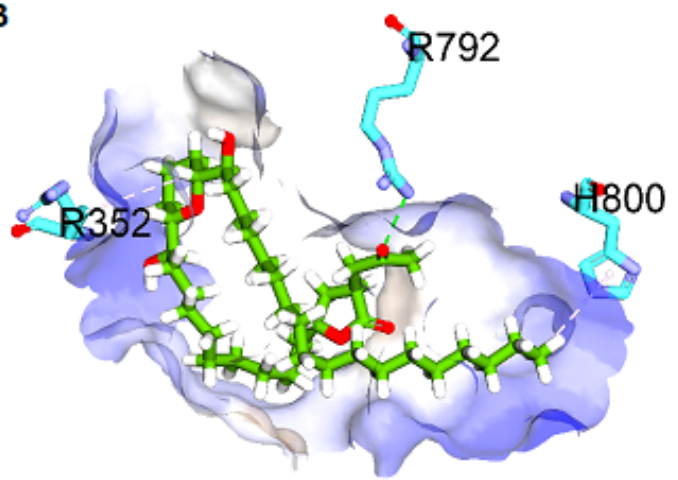

C

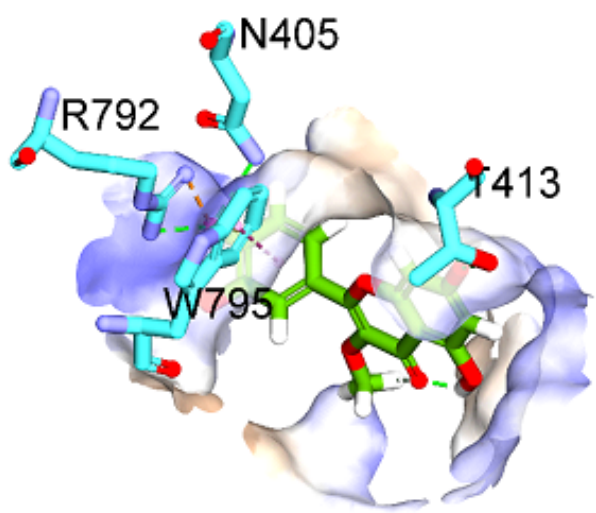

\section{Figure 5}

(A) 3D Interaction of 95 with NS5 RdRp DENV protein (PDB 3VWS); (B) 3D Interaction of 96 with NS5 RdRp DENV protein (PDB 3VWS); (C) 3D Interaction of 149 with NS5 RdRp DENV protein (PDB 3VWS). 

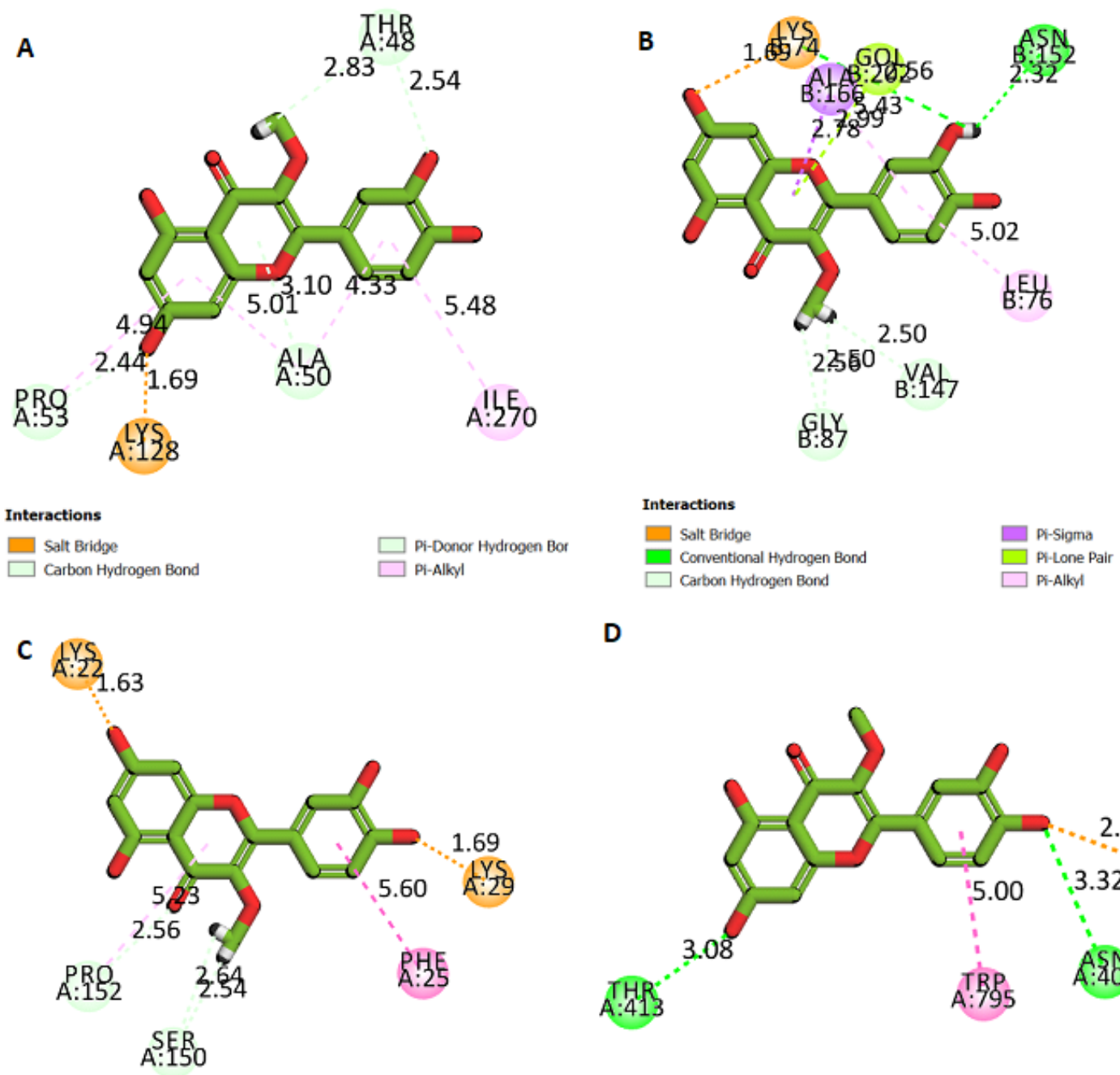

D
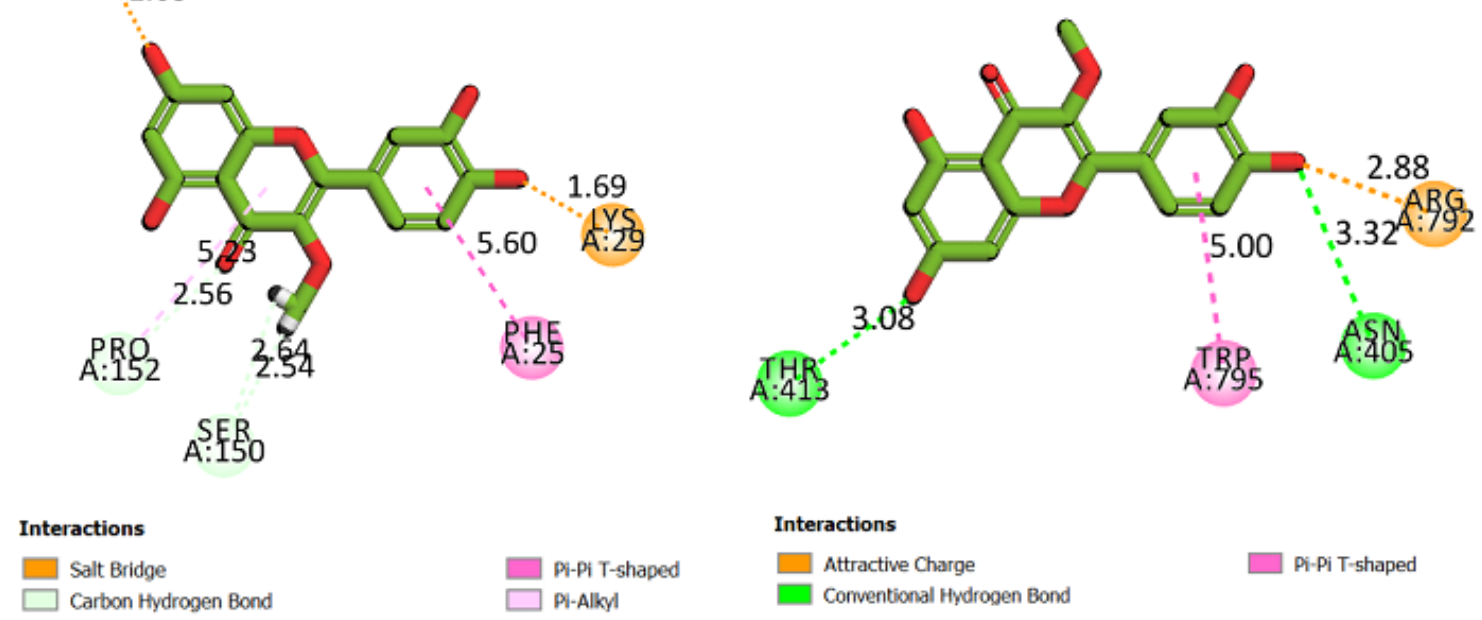

\section{Figure 6}

(A) 2D Interaction of 149 with E DENV protein (PDB 1OKE); (B) 2D Interaction of 149 with NS3/NS2B DENV protein (PDB 2FOM); (C) 2D Interaction of 149 with NS5 Methyltransferase DENV protein (PDB 1R6A); (D) 2D Interaction of 149 with NS5 RdRp DENV protein (PDB 3VWS). 


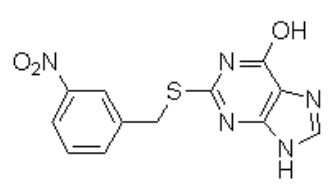

DO2<smiles>O=C(N/N=C/Cc1ccccc1)c1cc(/C=N/Nc2cccc(Br)c2)nc2ccccc12</smiles>

Compound $23 \mathrm{i}$

NSC14778

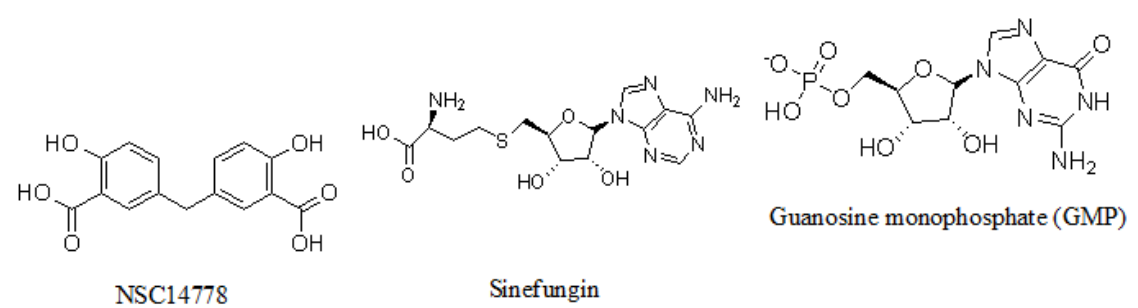

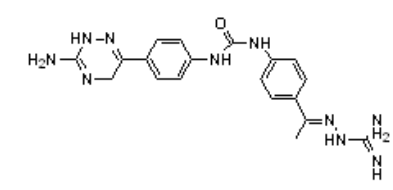

$\mathrm{PO} 2$<smiles>C/C(=N\Nc1ccccc1)c1sc(-c2cc(Cl)nc(Oc3ccc(Cl)cc3)c2)nc1C</smiles>

A5
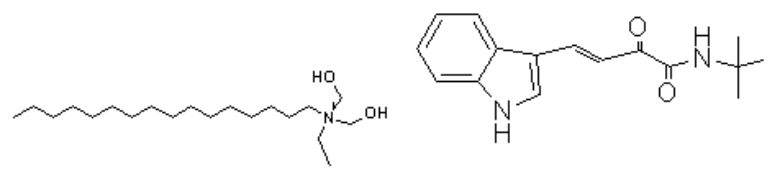

BP13944

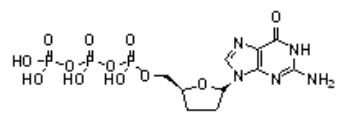

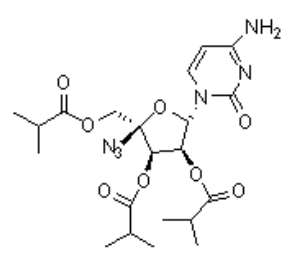

Bal apiravir

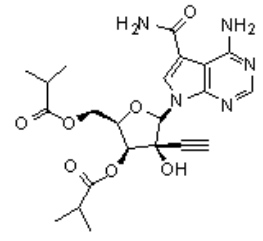

NITD 203

DdGTP

\section{Figure 7}

Chemical structure of top-ranked reported protein inhibitors. 


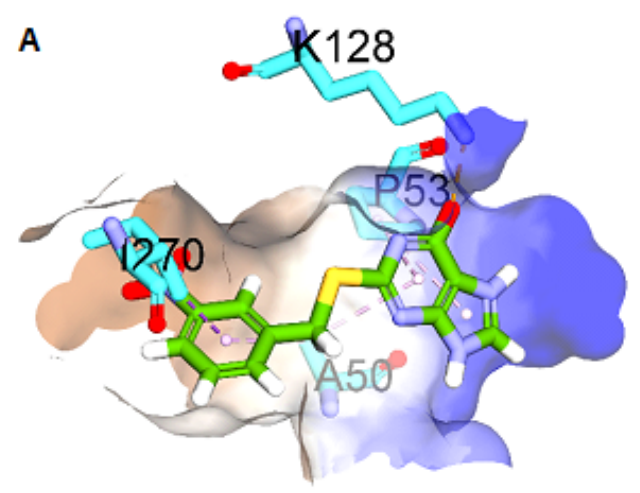

B
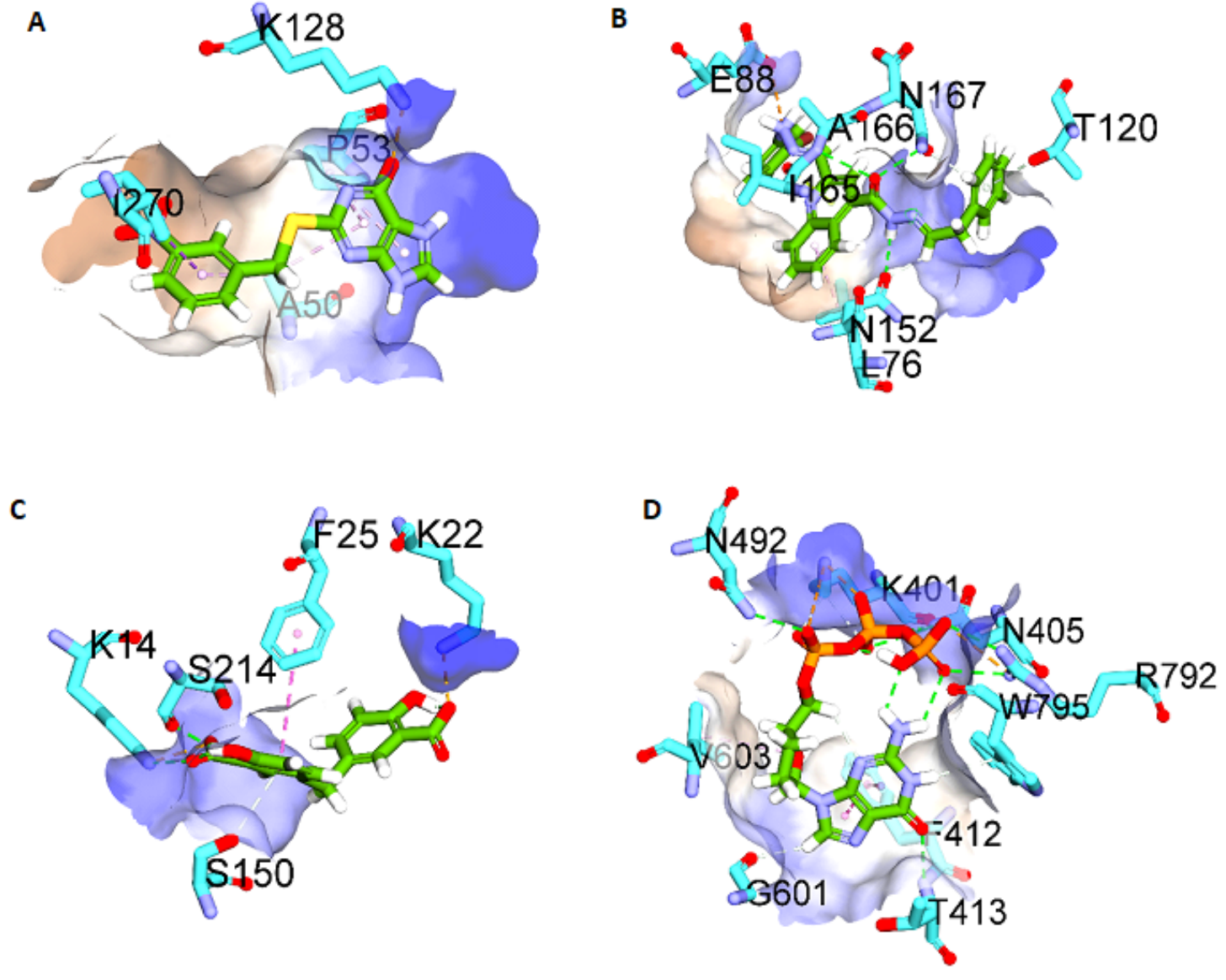

Figure 8

(A) 3D Interaction of D02 with Envelope DENV protein (PDB 1OKE); (B) 3D Interaction of compound 23i with cellular NS3/NS2B DENV protein (PDB 2FOM); (C) 3D Interaction of NSC14778 with NS5 methyltransferase protein (PDB 1R6A); (D) 3D Interaction of ddGTP with NS5 RNA-dependent RNA-polymerase DENV protein (PDB 3VWS).
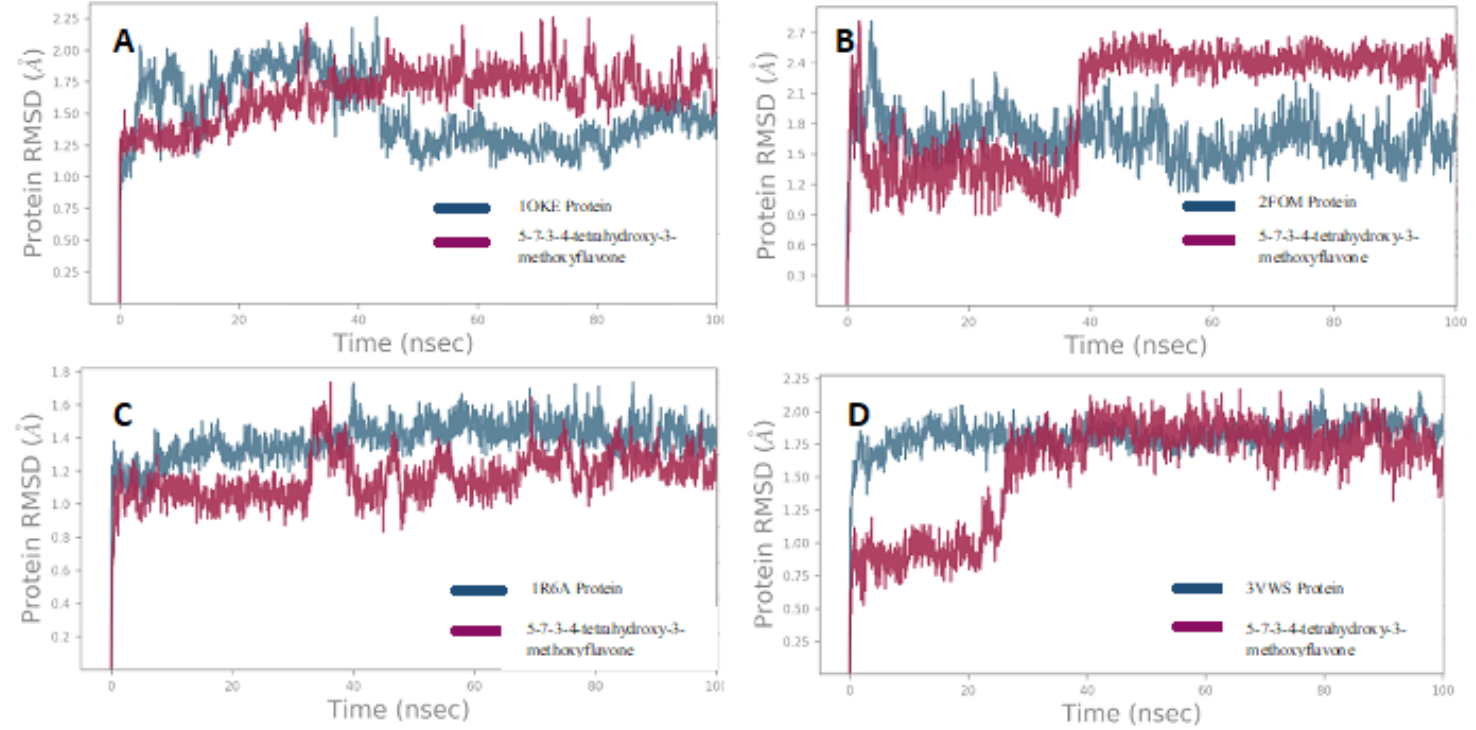

Figure 9 
(A) RMSD of 149 complexed with envelope protein (10KE); (B) RMSD of 149 complexed with NS3/NS2B protein (2FOM); (C) RMSD of 149 complexed with NS5 methyltransferase protein (1R6A); (D) RMSD of 149 complexed with NS5 RdRp protein (3VWS).
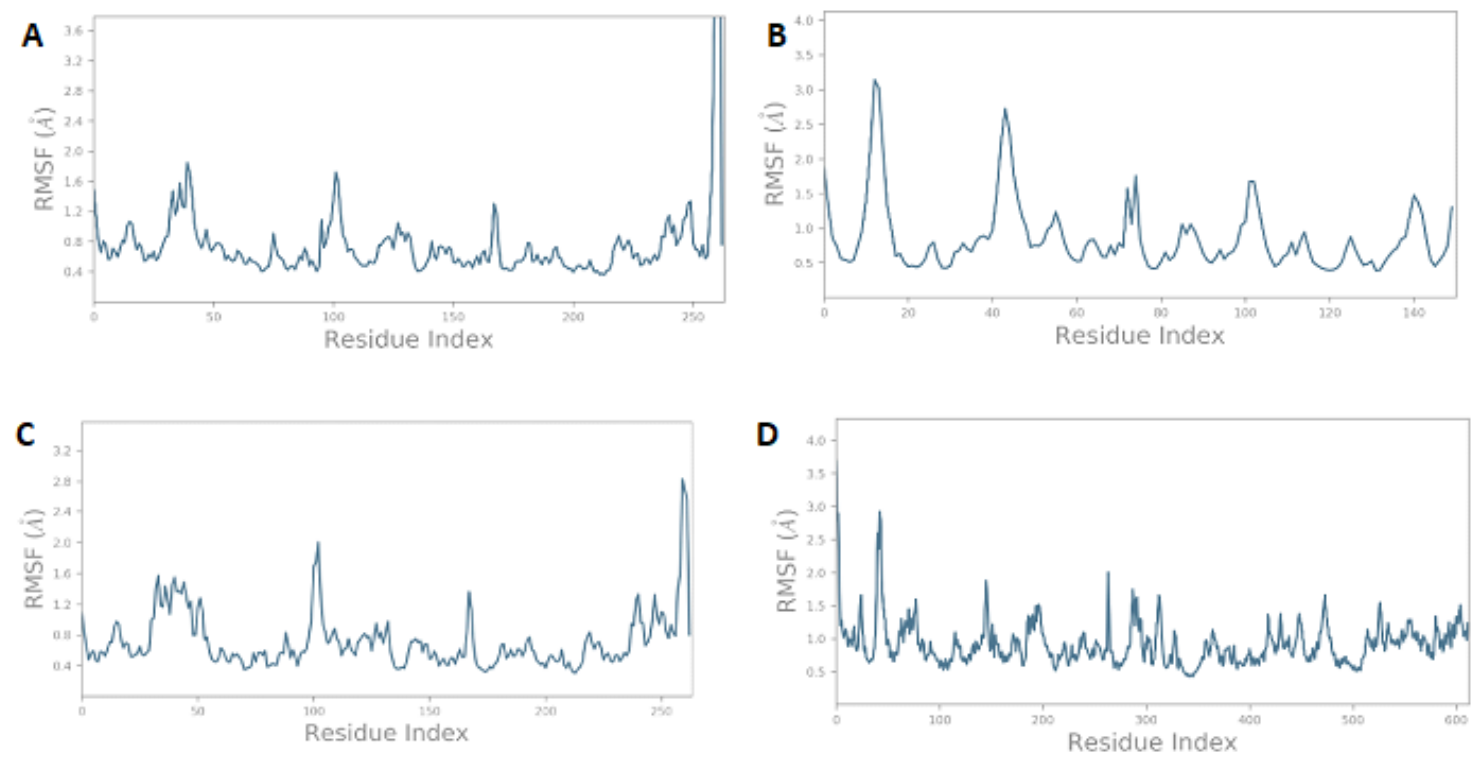

\section{Figure 10}

(A) RMSF of 149 complexed with envelope protein (1OKE); (B) RMSF of 149 complexed with NS3/NS2B protein (2FOM); (C) RMSF of 149 complexed with NS5 methyltransferase protein (1R6A); (D) RMSF of 149 complexed with NS5 RdRp protein (3VWS). 
A<smiles>COc1c(-c2ccc(O)c(O)c2)oc2cc(O)cc(O)c2c1=O</smiles>

a

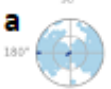

b

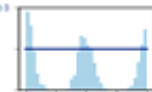

$(x)$

c
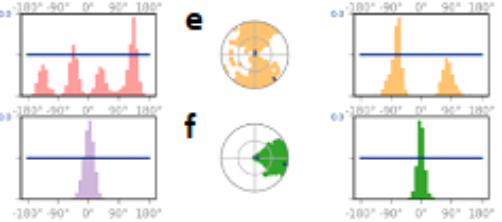

C<smiles>COc1c(-c2ccc(O)c(O)c2)oc2cc(O)cc(O)c2c1=O</smiles>

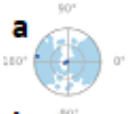

b
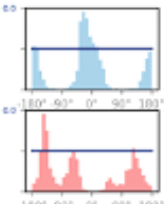

c

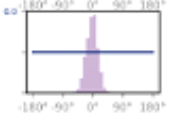

d

e
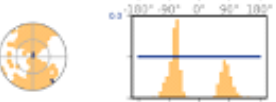

(c)

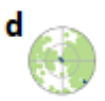

e

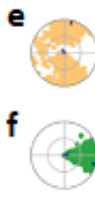

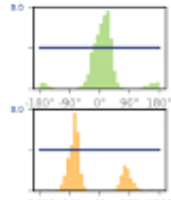

1
B<smiles>COc1c(-c2ccc(O)c(O)c2)oc2cc(O)cc(O)c2c1=O</smiles>

a

b

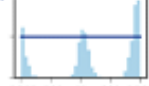

d

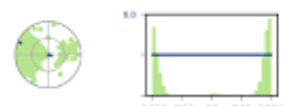

(a)

c

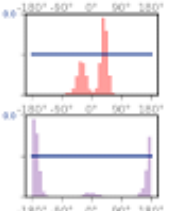

f

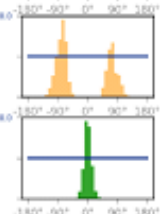

D<smiles>COc1c(-c2ccc(O)c(O)c2)oc2cc(O)cc(O)c2c1=O</smiles>

a

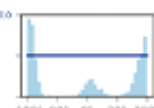

b

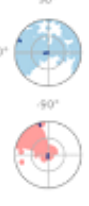

c
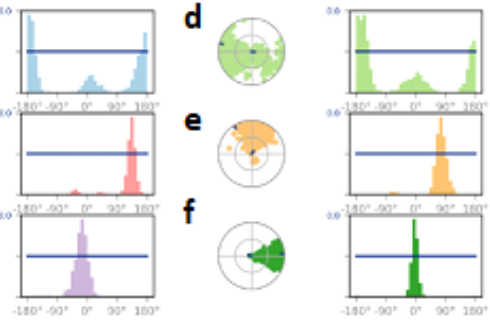

\section{Figure 11}

Graphics of the torsional of each rotatable bond of the ligand 149 in binding pocket of envelope dengue protein (1OKE) (A); NS3/NS2B dengue protein (2FOM) (B); NS5 methyltransferase dengue protein (1R6A) (C); and NS5 RdRp dengue protein (3VWS) (D) during MD simulations. 2D structure diagram of ligand 149 was shown with color-coded rotatable bonds on the top. The dial plots of the angle of each bond after simulation are displayed on the left, and the bar charts of the torsional probability as a function of angle shown on the right.
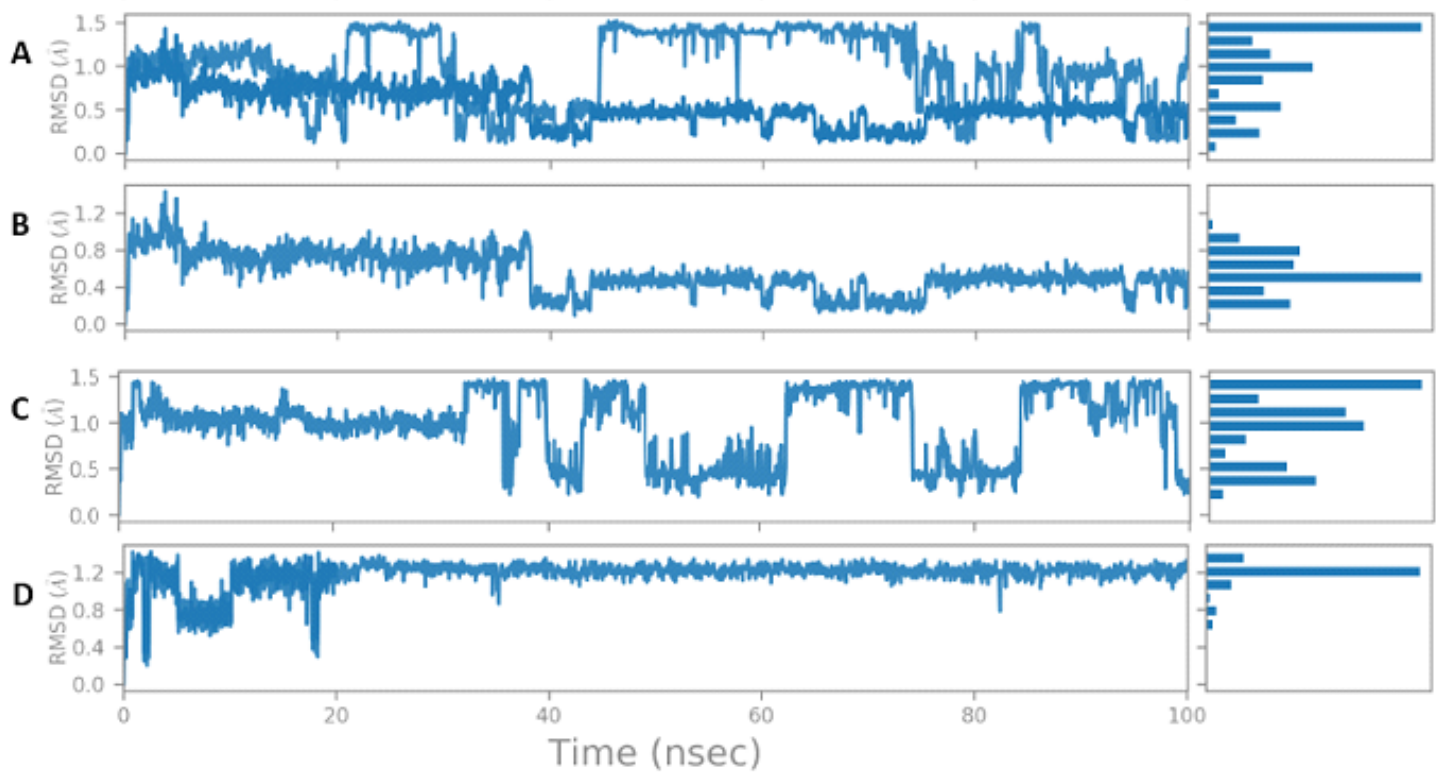
(A) RMSD ligand of 149 complexed with envelope protein (1OKE); (B) RMSD ligand of 149 complexed with NS3/NS2B protein (2FOM); (C) RMSD ligand of 149 complexed with NS5 methyltransferase protein (1R6A); (D) RMSD ligand of 149 complexed with NS5 RdRp protein (3VWS).

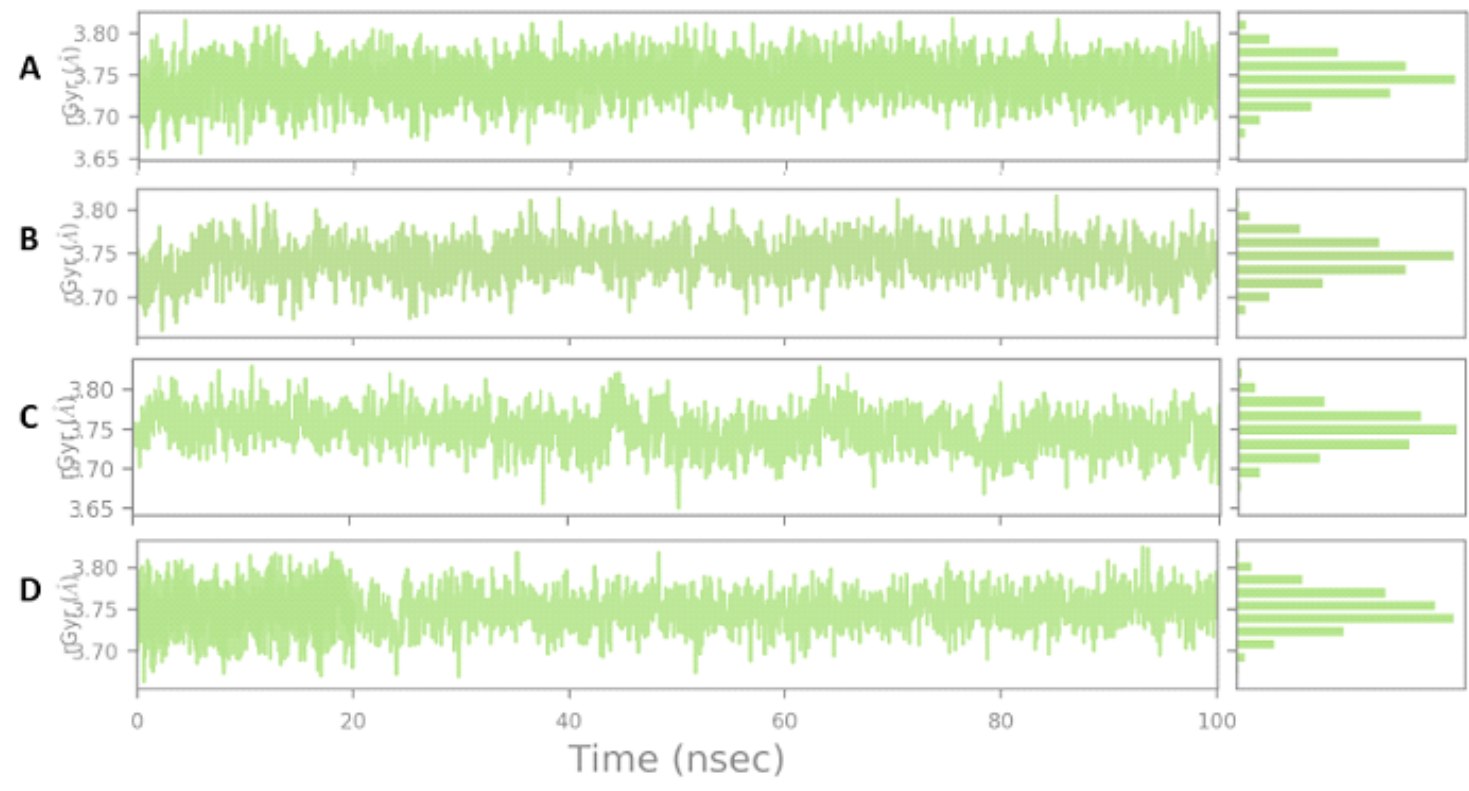

\section{Figure 13}

(A) rGyr of 149 complexed with envelope protein (1OKE); (B) rGyr of 149 complexed with NS3/NS2B protein (2FOM); (C) rGyr of 149 complexed with NS5 methyltransferase protein (1R6A); (D) rGyr of 149 complexed with NS5 RdRp protein (3VWS).

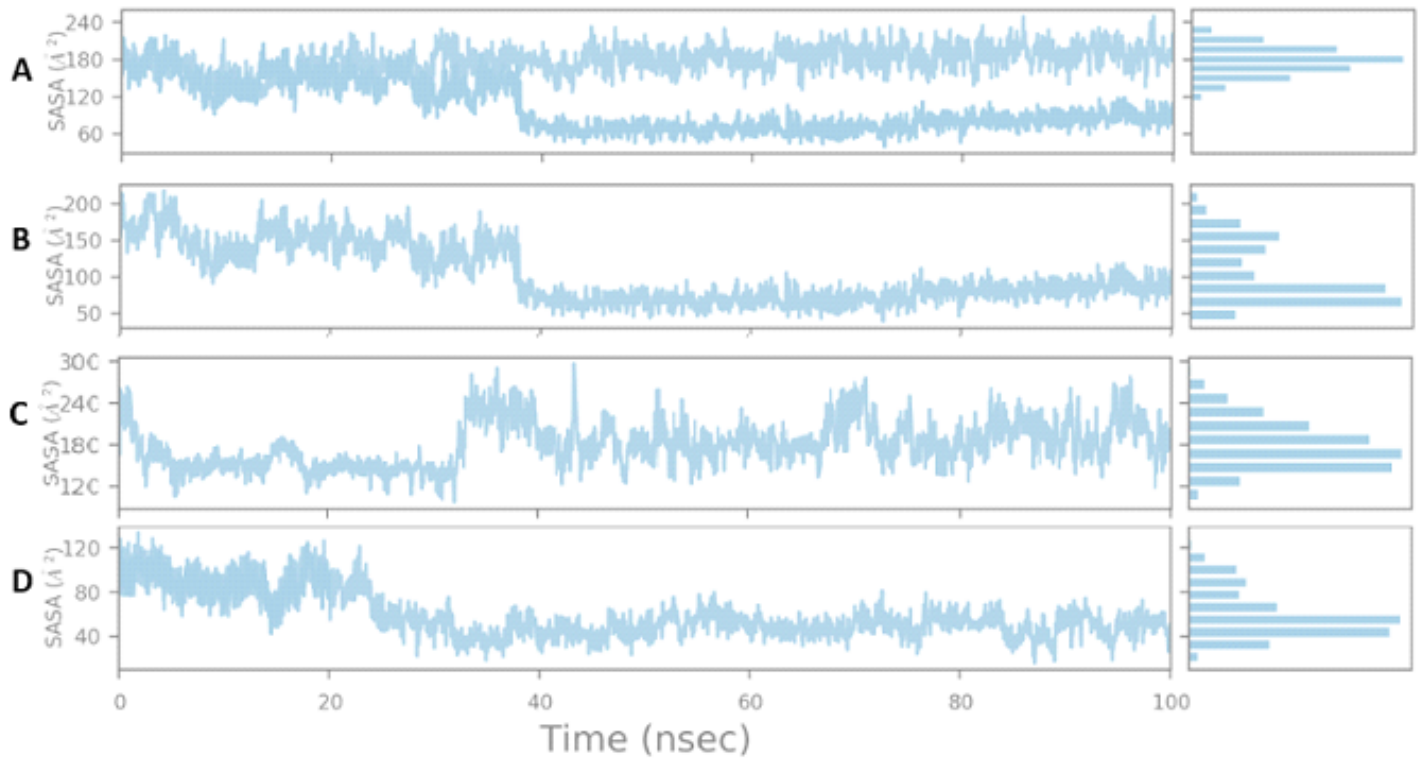

Figure 14

(A) SASA of 149 complexed with envelope protein (1OKE); (B) SASA of 149 complexed with NS3/NS2B protein (2FOM); (C) SASA of 149 complexed with NS5 methyltransferase protein (1R6A); (D) SASA of 149 complexed with NS5 RdRp protein (3VWS). 

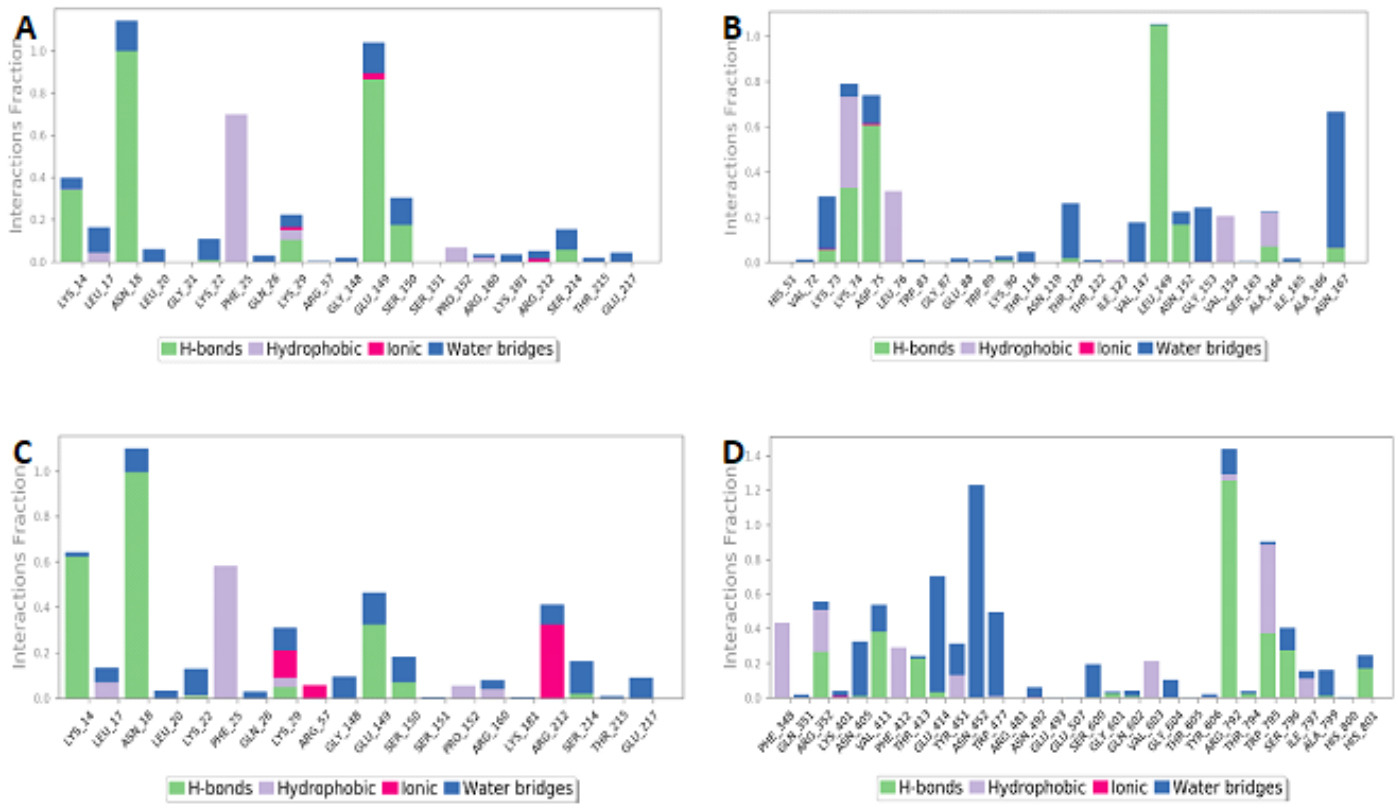

Figure 15

Protein-ligand contacts of compound 149 with envelope protein (1OKE) (A); NS3/NS2B protein (2FOM) (B); NS5 methyltransferase (C); NS5 RdRp protein (3VWS) (D). 


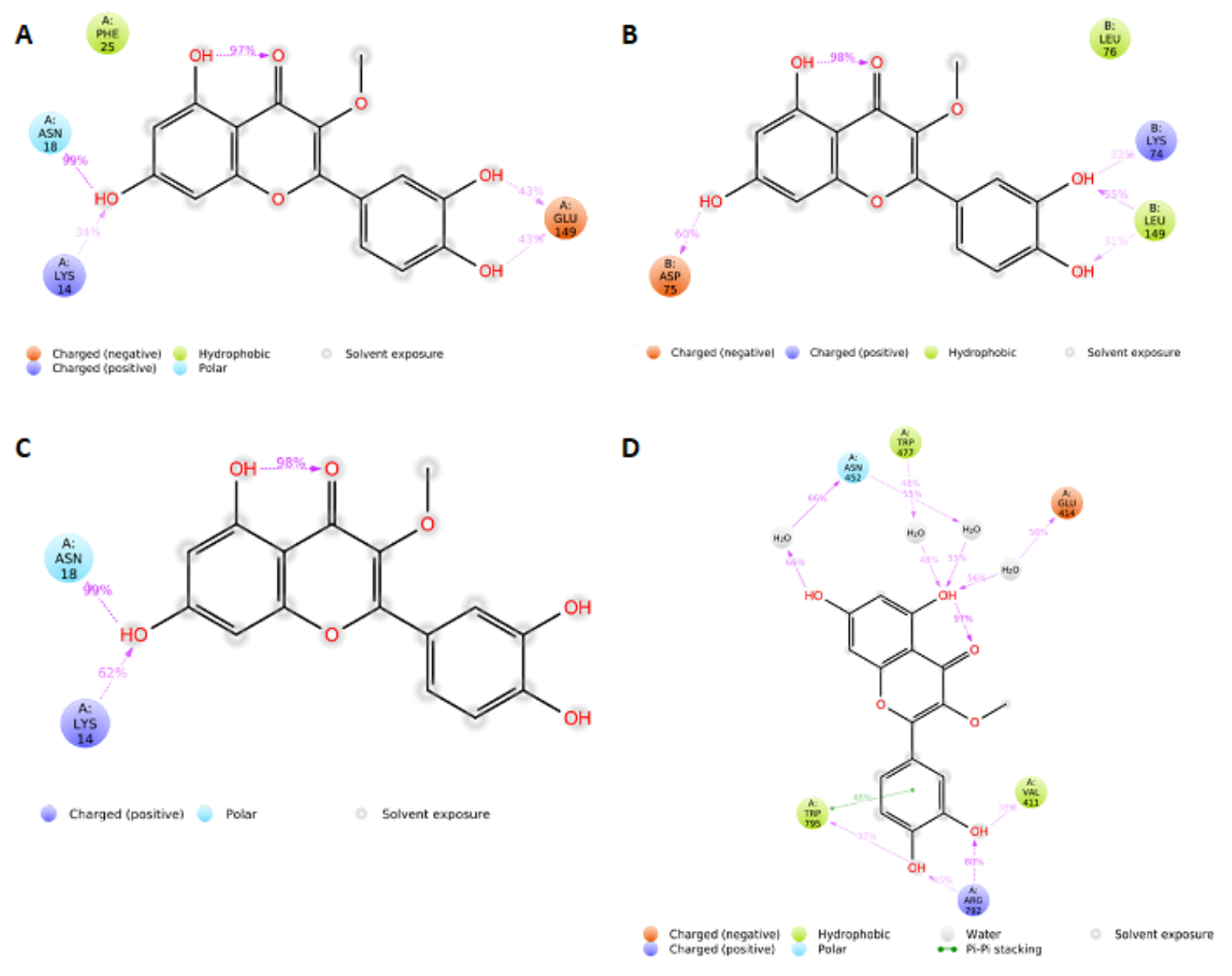

\section{Figure 16}

Ligand protein contacts of 149 with Envelope protein (1OKE) (A); NS3/NS2B (2FOM) (B); NS5 methyltransferase (1R6A) (C); NS5 RdRp protein (3VWS) (D).

\section{Supplementary Files}

This is a list of supplementary files associated with this preprint. Click to download.

- SUPPLEMENTARYMATERIAL.docx 